\title{
Arqueología evolutiva y Filogenética cultural
}

\author{
Evolutionary archaeology and Cultural phylogenetics
}

\author{
Daniel García Rivero* \\ Departamento de Prehistoria y Arqueología, Facultad de Geografía e Historia \\ Universidad de Sevilla \\ C/ Doña María de Padilla, s/n, 41004, Sevilla. \\ garciarivero@us.es
}

Recibido: $12-12-2011$

Aceptado: 18-04-2012

\begin{abstract}
Resumen
Este trabajo intenta responder por qué la aplicación de la Teoría de la evolución darwiniana en Arqueología es posible y, sobre todo, relevante. Es decir, cómo se beneficia esta rama cientifica al considerar el estudio de la cultura material, y por extensión el cambio cultural, bajo el enfoque del pensamiento evolutivo. En esta línea, una vez explicados los puntos teóricos principales, se realiza una exposición básica sobre la aplicación de esta epistemología en nuestro área científica, centrándonos fundamentalmente en las tareas de clasificación y secuenciación de los datos arqueológicos e introduciéndonos en lo que puede llamarse Filogenética cultural.
\end{abstract}

Palabras Clave: Arqueología. Epistemología. Evolución. Filogenética cultural. Filosofía de la ciencia.Taxonomía.

\begin{abstract}
This paper attempts to answer why the application of the Darwinian Theory of Evolution to archaeology is possible and, moreover, relevant. That is, what this scientific field gains by considering the study of material culture, and by extension of cultural change, from the perspective of evolutionary thought. In this line, after explaining the main theoretical points, we develop an exposition on the application of this epistemology in our scientific area, focusing particularly on the tasks of classification and sequencing of archaeological data and thus entering into the field of Cultural Phylogenetics.
\end{abstract}

KEY words: Archaeology. Epistemology. Evolution. Cultural Phylogenetics. Philosophy of Science. Taxonomy.

Sumario: 1. Breves notas sobre la diversidad filosófica en el estudio del cambio cultural humano. 2. El concepto de evolución darwiniana como herramienta científica arqueológica. 3. El estudio darwinista de la evolución de los rasgos y sistemas culturales. 4. Taxonomía filogenética. 5. Estudios filogenéticos culturales. 6. Discusión. 
... [the] formation of different languages and of species, and the proofs that both have been developed through a gradual process, are curiously parallel... We find in distinct languages striking homologies due to community of descent, and analogies due to a similar process of formation.

(Darwin 1871: 59-60).

\section{Breves notas sobre la diversidad filosófica en el estudio del cambio cultural humano ${ }^{1}$}

Las epistemologías con las que se ha interpretado la parte estrictamente no genética de los individuos y grupos humanos, esa que ahora podemos llamar cultural -y que no supone confrontación ni incompatibilidad antagónica con aquella biológica-, han sido muy numerosas. En lo que respecta particularmente a la Arqueología, ciencia histórica que debería entrar en comunión con otras más o menos similares para el propósito de explicar mejor nuestro pasado y presente -como la Antropología, la Biología y la Psicología, entre otras-, también los enfoques teóricos y paradigmas de pensamiento utilizados desde hace décadas son muchos y, sobre todo, diversos; por citar algunos de los más extendidos en la Arqueología española -algunos tienen más de epistemologías, de cuerpos teóricos más o menos fundamentados, y otros tienen más de paradigmas o modelos explicativos más asépticos y puntuales-, recuérdese por ejemplo el Historicismo Cultural, el Materialismo Histórico, la Nueva Arqueología procesualista $\mathrm{y}$, más recientemente, el Posprocesualismo. Todos éstos, y otros no citados con menos allegados, han proliferado más en unos determinados momentos o coyunturas de nuestra ciencia, y también más en unas ramas cronológicas o especialidades que en otras, dejándose llevar -el éxito relativo entre esas epistemologías- por las mareas e inercias de las tradiciones y modas de hacer ciencia, a veces irreflexivas, cuando no por intereses personales e ideológicos.

Al margen del porqué de la desigual aceptación de una u otra epistemología en Arqueología, lo que sí es cierto es que esta variabilidad de pensamiento es natural, lógica y, a todas luces, positiva para nuestra propia ciencia. Es natural y lógica porque, refiriéndonos a pilares filosóficos básicos, difícilmente uno que piense por ejemplo que el mundo y la vida están sujetos a leyes universales objetivas podrá convencer a otro que, por el contrario, piense que cada sujeto de la vida tiene una perspectiva distinta de la misma y, por ello, rehúse la búsqueda de leyes generalistas de tal tipo; la misma dificultad tendría el segundo para persuadir al primero. (Este debate, bien conocido, puede ejemplificarse con las perspectivas encontradas de los filósofos T. S. Kuhn y K. Popper). Figúrese, si la confrontación existe casi irreconciliablemente en tan básicas esferas reflexivas, cuánto pueden distanciarse las posturas conforme subimos en la escala del discurrir de los pensamientos y planteamientos sobre cuestiones históricas particulares. Por otro lado, es positiva -la variedad teórica existente- porque permite ir considerando casi todos los rincones, casi todas las posibilidades, en ese análisis y explicación de los fenómenos naturales. Es decir, en función del volumen de variación de pensamiento, seguramente, tendremos más probabilidades de dar con alguna tecla que nos permita validar y asentar algún conocimiento.

Sin embargo, y aun con esa diversidad teórica, existe un factor común a prácticamente todas las corrientes de pensamiento arqueológico: mantienen intocable como principio filosófico la intencionalidad humana como único, o en el mejor de los casos principal, mecanismo provocador del cambio cultural. Esto lleva a que casi todas las epistemologías arqueológicas den crédito fehaciente de que la Historia se constituye mediante unos cambios direccionales progresivos predeterminados por los propios humanos. En fin, el resultado es que todas las áreas de conocimiento dedicadas al estudio de la cultura humana siguen trabajando con un modelo lamarckiano del cambio en la vida.

Resulta paradójico que habiéndose desacreditado éste -el modelo lamarckiano- para todo análisis científico de cualquier organismo o entidad sobre la Tierra, incluido el de sus comportamientos, lo acojamos sin miramiento alguno para el caso exclusivo de Homo sapiens, sobre todo para su conducta, aunque no para las de sus especies ancestrales. Al margen del (natural) peso de nuestras influencias religiosas, filosóficas y culturales, y por mucho que nos pese, no podemos mantener axiomáticamente la intencionalidad humana y el modelo lamarckiano si nuestro propósito es exclusivamente científico. Es decir, no podemos trabajar con la heurística de la ecuación "intencionalidad humana=cambio estimado" si ésta -la propia ecuación-no está demostrada científicamente, no siempre funciona.

La intencionalidad es sólo parte del comportamiento. Además, es parte de un comportamiento basado en nuestro sentido común, es decir, en una determinada forma culturalmente heredada de entender la experiencia cotidiana y de relacionar la acción humana con el propósito (Dunnell 1982, citado en Bentley et al. 2008: 115) que no existe en los sistemas de percepción sensorial de otras culturas humanas. La intencionalidad, la necesidad y el hábito, ya se demostró en su día con el conocido ejemplo del alargamiento del cuello de las jirafas, 
no producen por sí mismas el cambio, y menos aún el cambio que se estima vaya a ocurrir en el futuro. ¿Por qué, si no, todavía se nos resiste el hallazgo de curaciones a ciertas enfermedades que medran seriamente en las poblaciones humanas aunque se invierta una ingente cantidad de recursos humanos y económicos (de intenciones y propósitos) en investigación médica? La historia de la tecnología nos brinda numerosos ejemplos reales que corroboran la inexactitud del modelo lamarckiano ${ }^{2}$. La intencionalidad humana es, efectivamente, ni más ni menos que un mecanismo generador de variación, sobre la que luego puede actuar la selección -la cual explicaremos más adelante (O’Brien, Holland y Fox 2003: 205).

Sustituyendo y corrigiendo a la explicación lamarckiana, en Biología se ha validado científicamente un modelo darwiniano del cambio en la vida, que no sólo es válido para el estudio del cambio genético y orgánico sino también para el del cambio cultural. El modelo darwiniano del cambio no es que descarte directamente la posible influencia que sobre el cambio pueda producir la variación y plasticidad del comportamiento humano. Más bien, a lo anterior añade otras fuerzas más importantes como mecanismos provocadores del cambio; sin duda, la más importante de ellas es la que se conoce con el nombre de selección natural. Este modelo darwiniano ha quedado validado científicamente porque está contrastado empíricamente en diversos ámbitos de la vida. Por supuesto, lo está en las áreas biológicas orgánicas, y más recientemente se viene demostrando su verosimilitud con los datos disponibles en otros campos relativos al comportamiento, como por ejemplo en Etología y en Arqueología evolutiva. Además, este modelo, como veremos en el párrafo siguiente, es acorde con los valores científicos que los filósofos de la ciencia han apuntado en relación con la epistemología, el área de la filosofía que estudia cómo sabemos lo que -creemos que- sabemos (Ruse 2001: 25).

Si científicamente, pues, se ha validado, en detrimento del paradigma lamarckiano, un modelo darwiniano del cambio general de la vida, es lógico que éste pueda (y deba) usarse también para el análisis de nosotros mismos. (Imagínense que un astrónomo de la actualidad pretendiese explicar el Universo haciendo caso omiso de la forma elipsoidal, y no plana, de nuestro planeta, y lo mismo si hiciera oídos sordos a la posición relativa de la Tierra, y de otros astros, en relación con el Sol). Es verdad que resulta muy difícil desprenderse de algunas de las enseñanzas y los valores que vamos adquiriendo a lo largo de la vida, sobre todo aquellos aceptados en edades tempranas de la misma, pero hemos de tener en cuenta que la mayoría de ellos son valores morales y no científicos, y poco o nada tienen que hacer aquéllos en la ciencia. Los únicos que en ésta estarían a buen recaudo son los denominados valores científicos o epistémicos. Algunos filósofos de la ciencia han señalado cuáles son esos valores, y, aunque algunos de éstos son clasificados y nombrados de forma distinta según la importancia relativa otorgada por unos y otros pensadores, podemos citar ahora los siguientes: simplicidad, poder unificador, fertilidad, consiliencia de inducciones, coherencia interna y consistencia externa, falsabilidad popperiana y precisión predictiva ( McMullin 1983; Ruse 2001: 46-49). Esta última referencia -el libro de M. Ruse- constituye un ejercicio de reflexión magnífico que analiza detenidamente, en función de la existencia o no de valores científicos y morales, el cuerpo epistemológico darwinista y algunos de sus científicos más relevantes o conocidos.

\section{El concepto de evolución darwiniana como herramienta científica arqueológica}

Actualmente, la comunidad científica general dedicada al estudio del cambio en la vida está de acuerdo en que la Teoría de la evolución constituye la epistemología que aúna el mayor número de los valores científicos a los que hemos aludido anteriormente, además de ser la que lo hace de la forma más sencilla y armoniosa. Este paradigma evolutivo, aun siendo tan sencillo, posee un gran poder explicativo. El resorte heurístico de la episteme darwiniana puede generar fácilmente un gran volumen de hipótesis y discusión científica que además puede irse contrastando y refinando conforme a los principios de refutabilidad y construcción del conocimiento.

El enfoque teórico evolucionista permite poner en relación, bajo unos mismos parámetros de pensamiento, multitud de áreas de conocimiento; este paraguas darwiniano enlaza pues enfoques y métodos de multitud de áreas de estudio no sólo culturales sino de muchos campos científicos de diversa índole (Antropología, Arqueología, Biología, Genética, Lingüística, Medicina, Paleontología, Psicología, Sociología, entre otras), dando cuenta fehacientemente del potencial de conexión multidisciplinar o del valor epistémico del poder unificador.

Existe una muy abundante bibliografía que, en formas y alcances muy distintos, explica los principios teóricos generales de la epistemología evolucionista darwiniana, entre las que destacaría $E l$ origen de las especies de Ch. R. Darwin (1859) y La estructura de la teoría de la evolución de S. J. Gould (2004). Aquí y ahora nos limitaremos a sintetizar y definir muy básicamente cuál es el núcleo fundamental (o la idea central) de dicha epistemo- 
logía, y también cuáles son los requisitos fundamentales para poder aplicarla a cualquier campo de estudio.

En esencia, el darwinismo plantea que el soporte génico de la vida (genotipo) y todas sus expresiones posibles (fenotipo) son, al unísono, elementos mutables que cambian a lo largo del tiempo y del espacio. No existe la generación espontánea, o lo que es lo mismo, toda expresión de la vida, sea somática (cuerpos fisiológicos) o extrasomática (pautas de comportamiento, cultura material, etc.), es una modificación mayor o menor de algo preexistente. ¿Pero cómo se produce esa modificación y el cambio?

El concepto de evolución para los darwinistas se refiere a la noción según la cual la variabilidad de las poblaciones cambia a lo largo del tiempo y del espacio. Es decir, las frecuencias relativas de los diferentes rasgos (somáticos y culturales) que conforman las poblaciones (o sistemas integrados por diversas poblaciones) no permanecen constantes, sino que cambian con el paso del tiempo. Para los darwinistas, además, las fuerzas que gobiernan el cambio no residen exclusivamente en el interior de los organismos, tal y como podría entenderse desde el concepto de transformismo predarwiniano. (Éste es todavía el único o principal mecanismo provocador del cambio en el resto de los enfoques teóricos aplicados al estudio de la Prehistoria e Historia, en los cuales, según ya ha quedado anotado, rige un modelo lamarckiano del cambio cultural). Al margen de la variación interior de los organismos, producida por la mutación genética y por la innovación del comportamiento, el motor del cambio más importante para los darwinistas se localizaría fuera de los organismos. Aunque se discute en foros especializados sobre la posible existencia de varios mecanismos, sin duda el principal de ellos para el cambio darwinista es lo que se conoce como selección natural.

El concepto de selección se refiere a la situación eventual donde cualquier tipo de presión provoque un sesgo reproductivo diferencial entre los rasgos de una población (o entre las distintas poblaciones de un sistema). Dicha presión (adjetivada normalmente como "selectiva") supone una especie de embudo o cuello de botella que impide la replicación y descendencia de parte de la variabilidad existente en pro de una descendencia mayor de la parte restante de dicha variabilidad. Esta presión selectiva puede surgir a partir del efecto de un grupo de organismos o de variables ambientales más generales, y puede afectar solamente a una población de organismos o a un número elevado de poblaciones. De ahí que se diga que el cambio darwinista viene de fuera, porque las presiones selectivas surgen esporádicamente según las interacciones entre los elementos de un sistema.

La selección constituye pues el mecanismo principal según el cual las frecuencias relativas de rasgos y organismos van modificándose a lo largo del tiempo. Los rasgos u organismos que, por las circunstancias que sean, no logren reproducirse o replicarse, no dejarán descendencia o copias, más o menos modificadas, de sí mismos. Cuando un conjunto o población de rasgos u organismos similares (próximos en fisiología, conducta, filogenia, economía de la naturaleza, o lo que sea) no logre replicarse lo suficiente (el límite mínimo depende de las circunstancias que le rodean), se extinguirá en favor de otra serie de rasgos u organismos que en dicha coyuntura tenga mayor reproducción diferencial y que, por tanto, ocupará su lugar.

A esta idea de la selección pónganle tiempo y espacio geográfico, añadiéndole una multitud de otros mecanismos y variables influyentes, como pueden ser la mutación y variación, la deriva, la migración y colonización, y un sinfín de posibles relaciones y niveles de asociaciones entre organismos y poblaciones, y obtendrá lo que llamamos especiación: la emergencia de nuevas especies a partir de otras existentes.

Por tanto, y resumiendo, los factores fundamentales para que cualquier sistema pueda analizarse pues desde un punto de vista darwinista son: 1) herencia, es decir, que los taxones o rasgos que se replican hereden entre sí información codificada genética y/o culturalmente; 2) variación, es decir, que durante esos procesos de reproducción o replicación de taxones o rasgos (somáticos o de conducta) se produzca modificación, o lo que es lo mismo, que las copias descendientes no sean totalmente idénticas a los especímenes ascendientes; y 3 ) competencia entre taxones o rasgos, es decir, que entre las posibles variantes (poblaciones, individuos, estados somáticos o culturales) se produzca (provocada por una presión selectiva) una reproducción diferencial. La figura 1 ilustra básicamente el modelo fundamental anterior.

Si bien este esquema del cambio se había pensado en estos mismos términos desde hace mucho tiempo, los arqueólogos e historiadores, normalmente, le hemos prestado poca atención, creyendo erróneamente que nuestros menesteres (el comportamiento y la cultura material humanos) no tienen apenas que ver con el conocimiento que se ha venido demostrando y acumulando en otras áreas científicas. En Biología se denomina genotipo al ADN que sintetiza información molecular, la cual se expresa o materializa en los rasgos fenotípicos (colores de ojos, de pelo, etc.). En el caso de la cultura, hemos de entender como genotipo toda la información que se 


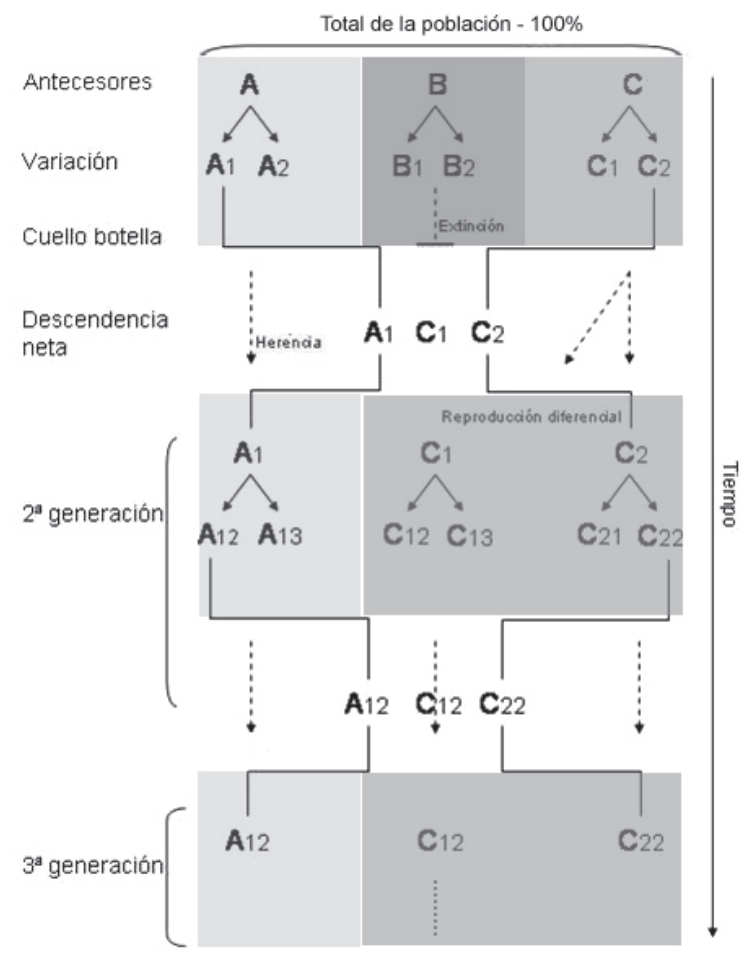

Figura 1.- En la parte superior de la figura aparecen tres letras (A, B y C) representando los tres primeros ancestros de nuestro ejemplo. Se podría tratar de tres organismos distintos, de tres pautas de comportamiento, de tres tipos cerámicos o de tres rasgos o variantes culturales posibles existentes en una población y generación dada. Para que el supuesto sea más ilustrativo y sencillo, el tamaño de la población permanecerá constante (sólo hay disponibles tres nichos o puestos en dicho ecosistema). El tiempo transcurre de arriba hacia abajo. En la primera generación se reflejan las diferentes fases del proceso, mientras que en las restantes sólo se señalan sus propios límites globales. Volviendo entonces arriba, debemos entender los rasgos A, B y $\mathrm{C}$ como las tres variantes culturales existentes en la primera generación, y que, dada una presión selectiva o cuello de botella, competirán entre sí por replicarse hacia la segunda generación. Esas tres alternativas estrechamente relacionadas entre sí (variantes cerámicas por ejemplo) están presentes inicialmente a partes iguales, es decir, cada una ocupa el $33 \%$ de la población. Todas ellas producen una variación de dos nuevos rasgos (por ejemplo, el rasgo A produce los rasgos A1 y A2). Se puede entender esto como la variación producida por el alfarero responsable de cada género cerámico. Sin embargo, no todos estos seis rasgos pueden reproducirse, porque la demanda crea una presión que ilustra eso de que las variantes "compiten" entre sí (la expresión "struggle for life" de Darwin). En la segunda generación de nuestro ejemplo sólo tres rasgos acaban constituyéndose como descendencia neta (A1, C1 y C2). Nótese cómo los dos rasgos deriva- dos del antecesor B se han extinguido. El tercio de la población que ocupaban ha sido sustituido ahora por los dos rasgos derivados del ancestro C (C12 y C13). Este incremento de $\mathrm{C}$ en la frecuencia relativa de la población a través de las generaciones (basta con sólo una) se denomina "reproducción diferencial" (el color gris más oscuro de la primera generación se extingue en pro del color gris de tonalidad media). Por tanto, en el paso de una generación las variantes iniciales se han modificado, han evolucionado, incluso algunas han sido sustituidas por otras. No obstante, podemos trazar líneas verticales (discontinuas) que nos muestran la fuerte relación genealógica que mantienen entre sí ascendientes y descendientes. Esto nos muestra la correlación de sus fitness o adaptabilidades, en el sentido de que una influye en buena medida sobre la sucesora. Efectivamente, este paso de información de una generación a otra se produce bajo diversos mecanismos de herencia. Si proseguimos hacia abajo nos encontramos con el mismo proceso en otra nueva generación, y así sucesivamente.

almacena y transmite culturalmente -por diversos mecanismos- entre los cerebros humanos, como por ejemplo las instrucciones alfareras que se codifican en las mentes de los artesanos; éstas se expresan fenotípicamente en los recipientes cerámicos, sobre los cuales opera la selección. Por tanto, los comportamientos y la cultura material son fenotipos expresados a partir de los cerebros, que funcionan de forma análoga al genotipo genético.

La traslación del modelo de la transmisión genética al estudio de la transmisión cultural no conlleva pensar, primero, que necesariamente las transmisiones de ambos tipos de información (genética y cultural) hayan de producirse siempre de forma independiente, pues ambas están, al fin y al cabo, relacionadas bajo un mismo sistema integrado: un organismo y, a un nivel superior, una población. En este sentido, somos conscientes de que el "genotipo cultural" probablemente englobe simultáneamente información cultural y genética. Segundo, la importación de dicho modelo al estudio de la cultura tampoco implica que la estructura y transmisión de la información cultural haya de producirse de formas totalmente idénticas a las del caso genético. Simplemente, dado que ese modelo ha permitido un gran avance en el conocimiento del mundo orgánico, está bien contar con un esquema inicial desde el que empezar a escudriñar cómo se estructura, se transmite y se almacena la información cultural, sobre todo a falta de otro modelo alternativo que cumpla mejor los propósitos científicos en nuestras áreas de estudio. Por tanto, y para terminar esta digresión, cuando usamos aquí las nociones de genotipo y fenotipo, estamos refiriendo e incluyendo los cuerpos físicos, 
sus comportamientos y, también, la cultura material que ambos producen (Bentley et al. 2008: 114).

En el total de las expresiones culturales de una sociedad podemos incluir un abanico amplísimo de rasgos: ideas, creencias, valores, patrones de conducta, lenguajes, objetos y utensilios materiales de muy diversa índole, etc. Como se ha anotado, no hay duda de que estos rasgos culturales no permanecen constantes a lo largo del tiempo, y tampoco a lo largo del espacio entre diversos grupos y sociedades. La diversidad que muestra el registro antropológico y arqueológico es el producto de la evolución de los rasgos culturales a lo largo del tiempo y espacio, los cuales cambian en ambas dimensiones mediante diversos mecanismos como la variación, la herencia, procesos de sesgos como la selección natural, la difusión, la transferencia horizontal, etc. Si en nuestros análisis pensamos en términos de poblaciones y creamos unidades culturales plausibles de ser medidas, como fonemas y morfemas en Lingüística, como atributos determinados en Antropología y como muchos rasgos del registro arqueológico, efectivamente bien ajustados a nuestras hipótesis y herramientas metodológicas, podremos ver cómo esas variantes culturales se distribuyen en y entre las poblaciones a lo largo del tiempo. Las distintas frecuencias relativas nos permitirán lanzar y contrastar hipótesis -efectivamente inspiradas en los principios darwinistas- sobre, por ejemplo, la reproducción diferencial de cada uno de estos rasgos a lo largo de las poblaciones y del tiempo y, por ende, podremos explicar los porqués de la proliferación y declive de unos y otros ítems arqueológicos, es decir, explicar el cambio cultural.

\section{El estudio darwinista de la evolución de los rasgos y sistemas culturales}

El estudio de la evolución de rasgos y sistemas culturales pasa primero por medir y rastrear esas propias unidades y después por analizarlas y explicarlas en función de los principios darwinistas del cambio -a través de las generaciones o transmisiones correspondientes, según la escala aproximativa que nos interese.

En cualquier caso, la búsqueda de la realidad histórica que pretendemos, la búsqueda de esas verdades históricas en sentido popperiano si se quiere, debe constituir un desarrollo ordenado de preguntas y respuestas, un trabajo sistemático que relacione adecuadamente nuestras conjeturas, hipótesis, inferencias y contrastes, de manera que consigamos un proceso acumulativo (y colectivo) de conocimiento.
Entre las primeras formas de razonamiento científico se encuentra el "método fundamentado en la analogía", que fue planteado por Platón y desarrollado posteriormente por Aristóteles. En efecto, la comparación entre dos partes, cantidades o conjuntos permite extraer inferencias sobre aspectos que ambos compartan. Hoy en día sería difícil imaginar una ciencia, la arqueológica inclusive, a falta del método comparativo. Es muy frecuente, por ejemplo, encontrar en la literatura arqueológica referencias a otros objetos más o menos similares al que se estudia o presenta, siendo muy habitual el uso del término "paralelo/s". Al fin y al cabo, lo que se hace es echar un vistazo al registro material conocido y ver qué conjuntos arqueológicos están más próximos y son más afines al que está bajo estudio.

Sin embargo, aunque nos resulte de gran ayuda, la aplicación del método comparativo, basado exclusivamente en la analogía, en la tarea de la clasificación tiene un serio problema, el cual, dicho sea de paso, no se ha percibido en la Arqueología española y en muchas otras: ¡no hemos atendido a las naturalezas de esas afinidades o similitudes entre objetos o conjuntos! Esto es: hemos olvidado considerar si los paralelos o analogías se deben al parentesco, porque ambos objetos o conjuntos proceden de un mismo ancestro común, o sin embargo se deben a otra serie de causas ${ }^{3}$. Por ejemplo, en la diáspora fenicia de principios del primer milenio a.C. a lo largo del Mediterráneo occidental, dos poblaciones diferentes -desconectadas entre sí porque salen en momentos distintos y arriban a destinos alejados- pueden compartir la similitud de albergar el conocimiento de la tecnología de la producción metalúrgica del hierro porque dicho rasgo cultural tecnológico ya existía en la población madre original de la que descienden ambos grupos. Sin embargo, la similitud que puedan compartir los conjuntos materiales de dos poblaciones distintas cualesquiera también puede deberse a un paralelismo y a una convergencia evolutiva -según las cuales se haya producido la emergencia independiente del mismo rasgo en taxones distintos y distantes-, pero también puede deberse dicha similitud a la transferencia horizontal del rasgo en cuestión entre las dos poblaciones porque ambas fuesen coetáneas. Esta última razón, la de la transferencia horizontal, es sencilla: las poblaciones romanas transfirieron muchos rasgos culturales y materiales a los numerosos grupos étnicos que se encontraron en diversas áreas geográficas. Muchos países actuales de todo el globo terráqueo han adquirido modas culturales de Estados Unidos, desde diversos productos alimenticios y materiales hasta incluso formatos televisivos de expresión artística. 
Por otro lado, un paralelismo se trata de un rasgo que emerge casualmente en dos lugares y momentos distintos, pero sin conexión filogenética, o lo que es lo mismo, sin compartir un ancestro común. Por ejemplo, la figura 2 compara algunos elementos del registro arqueológico de tribus indígenas americanas con algunos otros pertenecientes a la Prehistoria Reciente de la Península Ibérica. Se trata de un fenómeno casual que ha llevado a un paralelismo entre dos poblaciones o culturas aparentemente incomunicadas, tanto geográficamente (mediante el océano Atlántico) como en el tiempo. En este ejemplo hipotético suponemos la incomunicación espacial y temporal de las dos sociedades expuestas, pero ¿qué ocurre cuando estamos tratando materiales arqueológicos del mismo continente y periodo? Discernir si los rasgos son similares debidos a paralelismos o a lazos de filiación comunes es prácticamente imposible, o al menos ambiguo. De ahí la grave flaqueza del criterio de la analogía por semejanza o similitud, pues de cara a establecer agrupaciones y clasificaciones es insuficiente e incorrecto. Por último, una convergencia evolutiva se refiere a un rasgo que se encuentra en dos lugares y momentos distintos, sin conexión filogenética alguna, pero cuyas emergencias se deben a procesos de adaptación similares en ambos casos. Efectivamente, se trata de un fenómeno similar al paralelismo, pero con la diferencia de que en la convergencia evolutiva la razón principal de que dicho rasgo se haya desarrollado en varias ocasiones responde a presiones selectivas similares en distintos entornos. Además, se supone, ocurre con mayor frecuencia que los paralelismos. (Incluso, seguramente muchos de los rasgos más o menos similares que clasificamos presuntamente como paralelismos deban su proximidad en realidad a convergencias evolutivas, solo que todavía no se han hallado las presiones selectivas correspondientes que los subyace.) Un ejemplo ilustrativo de convergencia evolutiva sería el rasgo "color de pelo o pluma" en distintos animales. La perdiz y búho nivales, así como el oso polar, cuentan con plumas o pelos de color blanco, fruto de las presiones selectivas existentes en un entorno de nieve. El color exterior de los organismos de estas especies se ha visto moldeado por la selección natural en las poblaciones que llegaron y se reprodujeron, a lo largo de las generaciones, en las regiones árticas. Este ejemplo demuestra la emergencia o modificación de rasgos hacia estados idénticos en diversas poblaciones que no comparten una historia reciente común. Es probable que, por ejemplo, la emergencia de sociedades productoras en diferentes núcleos primigenios a lo largo del planeta y algunos procesos de intensificación
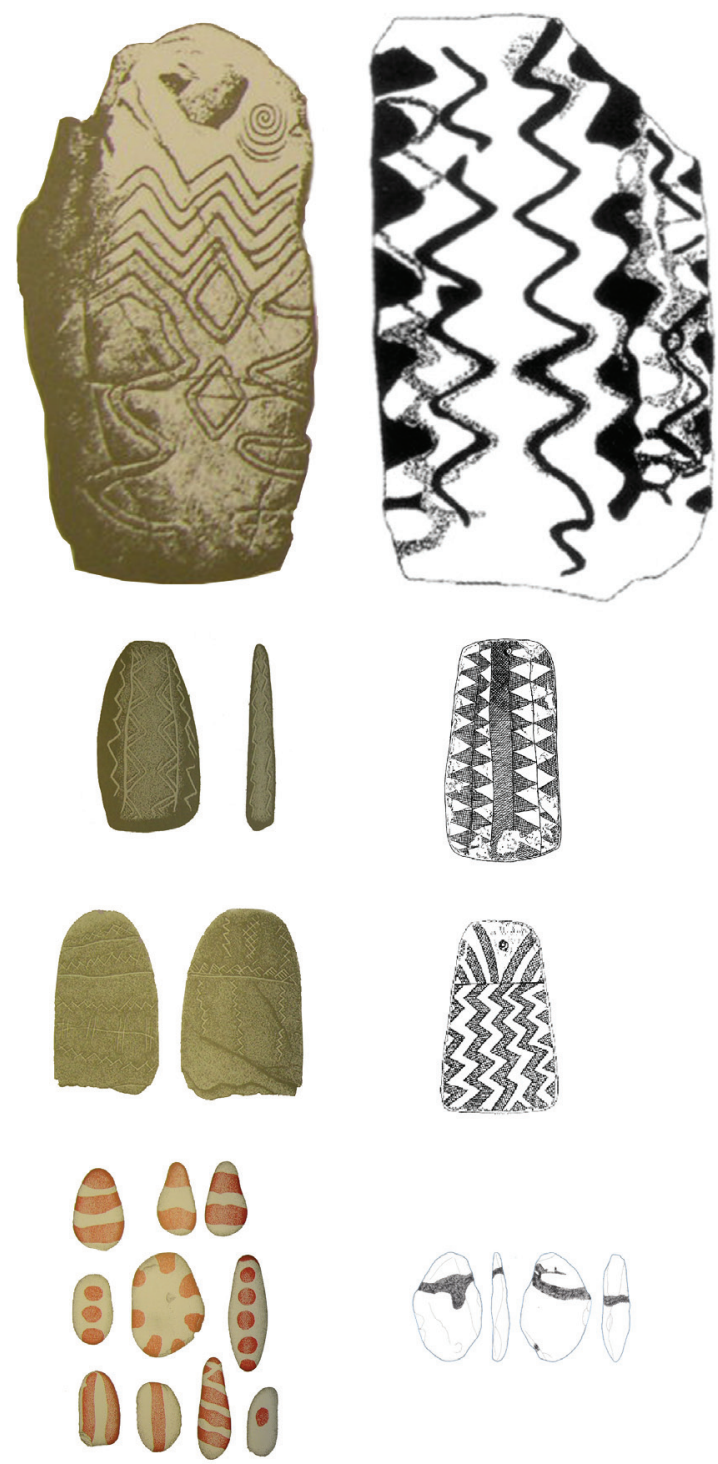

Figura 2.- La decoración de ortostatos megalíticos y de ídolos placas ibéricos es aparentemente muy similar -casi idéntica- a la realizada en marcadores espaciales y territoriales, y en otros artefactos en forma de placas, por sociedades indígenas americanas. Igual ocurre si comparamos el hecho de decorar mediante pinturas los cantos guijarros americanos con aquellos otros del Aziliense cantábrico. Esta figura compara algunos elementos del registro arqueológico de tribus indígenas americanas (columna de la izquierda) con algunos otros pertenecientes a la Prehistoria Reciente de la Península Ibérica (columna de la derecha). Se trata de un ejemplo que ilustra un paralelismo o una convergencia evolutiva entre dos poblaciones o culturas completamente incomunicadas, tanto geográfica como temporalmente. Figura elaborada a partir de Breuil (1935), Carpenter y Schuster (1988) y Lillios (2004). 
de la desigualdad social en grupos amplios y entornos específicos puedan deberse a convergencias evolutivas.

En todo caso, el desentendimiento de este punto en Arqueología no es sorprendente, puesto que tal reflexión necesita de haber pensado y asumido previamente un modelo evolutivo del cambio y sucesión de las especies, y por tanto de la clasificación de éstas (y de los taxones arqueológicos), y dicho modelo, que tanto tiempo hace que se practica -de forma predominante y casi exclusiva- en Biología y en otras áreas científicas de carácter histórico, se ha considerado poco en nuestro campo. Como expondremos más adelante, la Filogenética es la única metodología de ordenación que se enfrenta y analiza detenidamente esta cuestión, y, por tanto, permite unas clasificaciones y propuestas de secuencias históricas más consistentes y rigurosas. Pero en este momento que hablamos de secuencias, pasemos al siguiente método de razonamiento científico que ahora nos interesa.

El segundo medio fundamental de inferencia en las ciencias históricas es el "método de secuenciación". Conforme a éste, los diferentes taxones y conjuntos bajo estudio se ponen en común en un mismo proceso histórico. Este método se utiliza también desde antiguo en la ciencia general, y antropólogos y arqueólogos han hecho uso de él desde la segunda mitad del siglo XIX y especialmente en el siglo $\mathrm{XX}^{4}$; actualmente resultaría inconcebible una Biología e Historia sin las múltiples técnicas de secuenciación. Lo que pasa, aquí también, es que apenas hemos considerado en Arqueología la naturaleza de esas secuencias. Normalmente, se han pensado propuestas de evolución histórica únicamente lineales, en las que una cultura ha pasado por diferentes estadios a lo largo de una misma línea recta (secuencia filética). Así se ha planteado incluso la historia de nuestro pasado homínido hasta hace algunas décadas; hoy, las propuestas históricas sobre dicha evolución son bien distintas, representaciones gráficas a modo de árboles basadas en un modelo divergente de la vida donde desde un mismo tronco emergen diversas ramas y multitud de varas.

El tercer medio importante para el razonamiento científico es el "método experimental", que no es otra cosa que la propia experimentación de las deducciones e hipótesis. Éste se remonta al menos a G. Galilei, y su procedimiento estandarizado actual fue filosóficamente desglosado por K. Popper. Aunque normalmente confundimos y relegamos la ciencia experimental a las áreas o ramas generalmente denominadas exactas (Matemáticas, Física, Química, etc.), es posible hacer ciencia experimental (en el sentido de la comprobación) en las ramas o ciencias históricas (Antropología, Arqueología, Biología, Paleontología, etc.), aunque efectivamente parte de la conducta humana pueda haberse extinguido; la única diferencia es que las preguntas y comprobaciones deben ser indirectas (apoyadas en otras dimensiones de los datos). Efectivamente podemos realizar cuantas inferencias queramos, pero es necesario contrastarlas. La comprobación de esta información, inducida a partir de los datos o deducida según dimensiones colaterales de una explicación subyacente, permite eliminar la incertidumbre sobre la propia validez de las inferencias. Aunque no todas, gran parte de las tendencias habituales en Arqueología adolecen también de cierta flaqueza en este punto. Valga citar la que todavía es una de las corrientes predominantes en la Arqueología española, el Historicismo Cultural. (La mayoría de arqueólogos que se creen asépticos en cuestiones de epistemología son por lo general historicistas.) Esta corriente propone relaciones de similitud y proximidad entre conjuntos y culturas arqueológicas, en muchos casos acertadas - una cualidad de muchos historicistas es una intuición extraordinaria para advertir inferencias certeras-, sin embargo no dispone por sí misma de un resorte heurístico interno que le permita zanjar objetivamente muchos de los interrogantes históricos planteados, y por eso ha de echar mano frecuentemente de la analogía histórica, es decir del registro histórico, arqueológico, antropológico, etc. de otras poblaciones o culturas con similares circunstancias a las del caso bajo estudio aunque aquéllas estén alejadas de éste en el tiempo y el espacio. Se puede decir como conclusión que muchas de las tendencias teóricas aplicadas actualmente en Arqueología no cuentan con métodos de comprobación directa (interna) de sus hipótesis.

Llegados a este punto, hemos plasmado ya algunas de las ventajas más notables que supone el pensamiento evolutivo (y algunas de las desventajas correspondientes de otras perspectivas teóricas) en relación con algunos de los métodos científicos fundamentales que usamos en Arqueología. Recapitulando, el modelo de cambio darwiniano, basado en la herencia, variación y reproducción diferencial, se ajusta de una forma más verosímil a los datos disponibles actualmente y a los fenómenos suficientemente conocidos en numerosas áreas científicas que el modelo lamarckiano, que es el que emplean el resto de teorías arqueológicas y el cual está basado exclusivamente en la intencionalidad o necesidad humanas. La teoría darwinista, además, posee todos los valores científicos sugeridos por los filósofos de la ciencia epistemológica, mientras que, en cambio, entre el resto de 
teorías aplicadas al estudio arqueológico, algunas cuentan solamente con varios de aquéllos y otras ni siquiera los consideran. El modelo darwiniano es, por lo que venimos diciendo, científicamente más correcto (y tiene mayor potencial de análisis) para el estudio de la transmisión y cambio cultural y, por tanto, para las tareas de secuenciación y clasificación del registro arqueológico. Muchos enfoques teóricos aplicados a la Arqueología disponen de modelos de análisis subjetivos, los cuales sesgan sus factores explicativos del cambio a sólo algunos de los mecanismos existentes en la naturaleza. Por ejemplo, sabemos de algunas corrientes que han explicado todo fenómeno histórico basándose sólo en la difusión, mientras que otras más recientes, quizás por un efecto de reacción emocional contra lo anterior más sustentado en modas irracionales que otra cosa, lo hacen solamente mediante el mecanismo de la innovación. Pero al margen de estas menudencias, existen otros problemas más extendidos y de mayor calado en el grueso de enfoques arqueológicos. Por ejemplo, no haber considerado las diversas razones posibles de por qué dos objetos o conjuntos arqueológicos pueden ser similares entre sí. Esto ha llevado a que las secuencias y clasificaciones arqueológicas se hayan basado sólo en el criterio ambiguo de la similitud, adoptando generalmente modelos unilineales y otros sin respaldo teórico y empírico, y no en los principios de las leyes de la transmisión de la información y herencia, como hace la metodología sistemática filogenética al amparo de la perspectiva evolutiva. Ésta, además, permite comprobar las secuencias clasificatorias y las hipótesis históricas subyacentes mediante una base numérica estadística acorde con el principio de refutación y con la sistematización y acumulación del conocimiento.

¿Por qué entonces es útil la aplicación de una Arqueología sistemática evolutiva? La razón principal es que permite alinear operativamente, bajo un modelo filogenético, un fundamento teórico congruente (evolución por descendencia con modificación) con la realidad histórica y variación del registro arqueológico, cuya sistematización permite el desarrollo ordenado y progresivo de conocimiento mediante inferencias y deducciones contrastadas. Teoría de la evolución (darwiniana) y Sistemática filogenética son acoplables y congruentes entre sí, pero también con la premisa de la búsqueda objetiva de una realidad histórica, de una verdad en el sentido popperiano. En términos ideales y heurísticos, posiblemente se trate de la herramienta de investigación con más potencial a día de hoy en el campo de la Arqueología, como ha ocurrido hace algunos años en la Paleontología.

\section{Taxonomía filogenética}

La inmensa mayoría de las clasificaciones que encontramos en las publicaciones y trabajos arqueológicos se engloban bajo una misma escuela taxonómica que los especialistas de la clasificación denominan "Fenética". Ésta se basa sólo y exclusivamente en el criterio de la similitud o semejanza entre los especímenes a agrupar para constituir grupos anidados inclusivamente en diversos niveles. Estas clasificaciones más o menos jerárquicas siguen el patrón taxonómico que desde 1735 empezó a establecer C. Linneo en su Systema Naturae. Esta base fundamental del estudio taxonómico sigue vigente hoy en día, sin embargo hace ya más de siglo y medio que en Lingüística y Biología se le añadió el concepto de la evolución, que la hace más fértil y operativa y más correcta científicamente. C. Linneo creyó que las especies y agrupaciones de organismos que clasificaba eran elementos totalmente estáticos, inmutables, creados por Dios con sus respectivas formas desde el inicio y hasta el final de los tiempos. Una vez que J. B. Lamarck (1809) y Ch. R. Darwin (1859), entre otros, demostraron que los organismos se modifican a lo largo del tiempo, hubo que dotar a este patrón taxonómico con un dinamismo antes totalmente ausente: el transformismo de Lamarck o la evolución por selección natural de Darwin. Lo que ahora realmente nos interesa advertir es que desde entonces las clasificaciones no podrían basarse ya sólo en la similitud global entre unos y otros organismos, sino que podría añadírseles una nueva dimensión que atañese a la propia información que se transmitía entre ellos. En el caso biológico, desde entonces, se refirieron las nociones de herencia y parentesco, y se realizó un esbozo gráfico y conceptual del árbol de la vida sobre el patrón inmutable -aunque de idéntica estructura- anterior.

Es a mediados del siglo XX cuando esta concepción taxonómica se consolida y formaliza metodológicamente, a manos de W. Hennig (1950; 1965; 1966), una vez se cuenta ya con un conocimiento más avanzado del soporte génico de la vida (información almacenada en los genes). Esta nueva escuela taxonómica se denominó entonces "Sistemática filogenética", aunque hoy en día se conoce con el nombre de "Cladística". Desafortunadamente, la mayoría de la taxonomía arqueológica practicada hoy en día, aun siendo esta labor una parte importantísima en nuestro trabajo, se ha quedado anquilosada en la escuela fenética y en el patrón inmutable linneano, obviando las implicaciones que los principios evolutivos tienen también sobre la cultura material ${ }^{6}$. (Ya habíamos visto atrás cómo no atiende por ejemplo a las diferentes razones posibles de la 


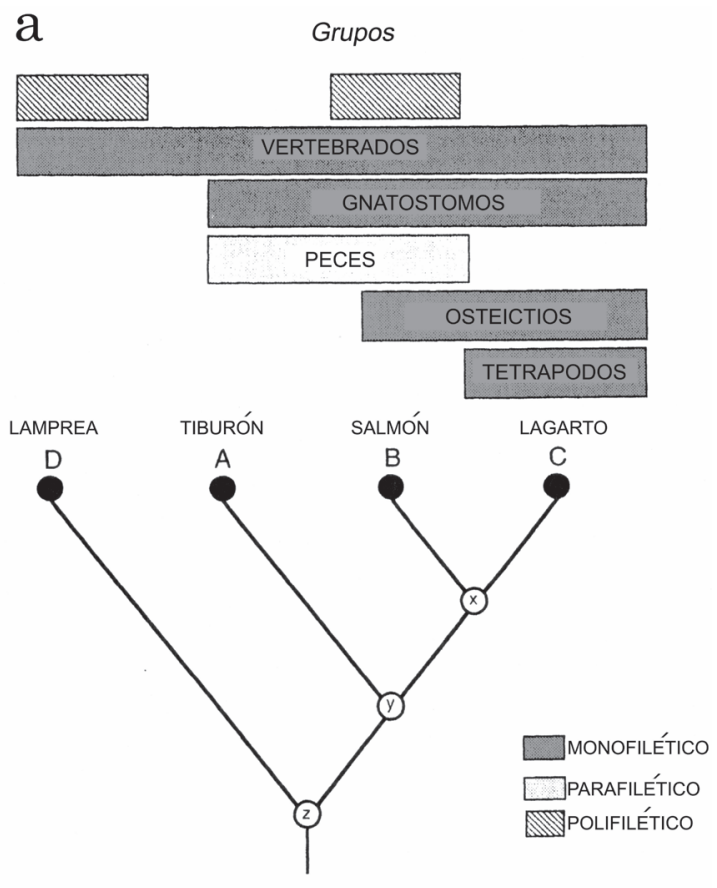

b

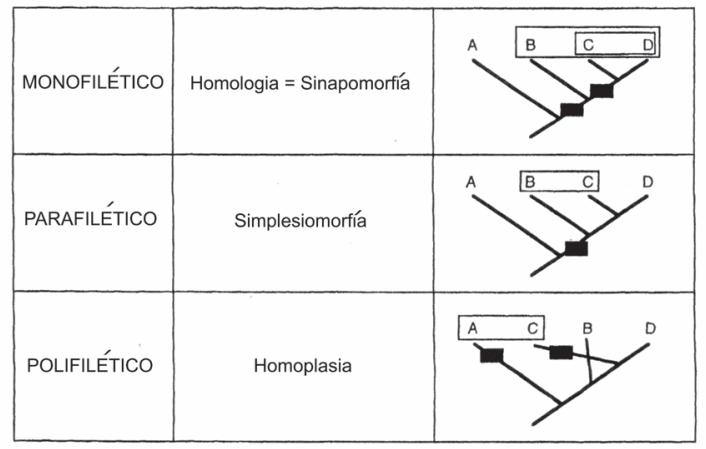

Figura 3.- (a) Tipos de agrupaciones taxonómicas; (b) tipos de caracteres reconocidos para sus construcciones respectivas. Figura elaborada a partir de Kitching et al. (1998, Figs. 1.8 y 1.10.).

semejanza entre dos rasgos u objetos.) La Fenética, pues, flaquea porque le falta un modelo teórico subyacente, convirtiéndose por tanto en un método taxonómico vacío que nada puede contarnos sobre sus propias propuestas de clasificación. En cambio, en Cladística, la evolución darwiniana suministra un marco teórico para el sistema taxonómico linneano, y así sistema y teoría se interconectan (cf. O'Brien y Lyman 2003: 112). Sin seguir profundizando aquí en esto porque nos desviaríamos en exceso de la línea central de este artículo, puede consultarse un trabajo donde he desglosado, pensando en estudiantes y especialistas de la Arqueología, los puntos teóricos principales de la clasificación y de las tres escuelas taxonómicas existentes (García Rivero 2010b).

La única metodología taxonómica que existe hoy para estudiar la transmisión es la Filogenética. La Filogenética, pues, se basa en la transmisión, ya sea ésta genética, somática o cultural. Los estudios filogenéticos basados en información genética o somática son muy frecuentes, y pueden verse en aproximaciones cercanas a nuestro campo, como pueden ser las propuestas clasificatorias sobre la evolución de homínidos. Éstas suelen utilizar información morfométrica concerniente a diversas partes de los restos paleontológicos, o también información genética extraída de las cadenas genómicas de los mismos. Las aproximaciones filogenéticas que ahora denominamos culturales pueden basarse, por ejemplo, en rasgos extrasomáticos como pueden ser determinadas pautas culturales y la propia cultura material ${ }^{7}$.

En su concepción básica, la Filogenética utiliza, de cara a establecer agrupaciones, la información transmitida según las leyes del parentesco, es decir, la información transmitida verticalmente, por ejemplo, de padres a hijos, de alfareros maestros a aprendices, de una generación a la siguiente en una misma población, etc. La Cladística obvia los caracteres análogos, es decir, aquellos de igual estado entre diversas especies sin que exista evidencia alguna de genealogía entre ellas. En cambio, utiliza los caracteres homólogos, concretamente los que se denominan "caracteres derivados compartidos" o, en argot filogenético, "sinapomorfías". Éstas se refieren a los rasgos que, en la tarea de agrupación, comparten todos los taxones hermanos junto con su ancestro común, pero no el ancestro previo a éste -en ese caso serían "caracteres compartidos ancestrales". Las sinapomorfías constituyen, también en argot técnico, "grupos o clados monofiléticos". Este tipo de agrupación es el único criterio que concibe la Cladística para ordenar taxones bajo el modelo taxonómico darwiniano (Fig. 3).

El procedimiento básico para la construcción de un cladograma ${ }^{8}$ es lo que se conoce como "argumentación hennigiana" o "regla de inclusión/ exclusión", por la cual se conjuga en una misma representación la información disponible en todas las series de transformación de los caracteres o rasgos considerados (Fig. 4).

Dentro de lo que generalmente se denomina Filogenética, además de la Cladística, existe otra escuela taxonómica que se llama "Taxonomía evolutiva". Ésta surge poco después que la Cladística, aunque se desarrollan ambas paralelamente. Los trabajos pioneros de este nuevo enfoque taxonómico se deben a E. Mayr (1969). Si la Fenética se 

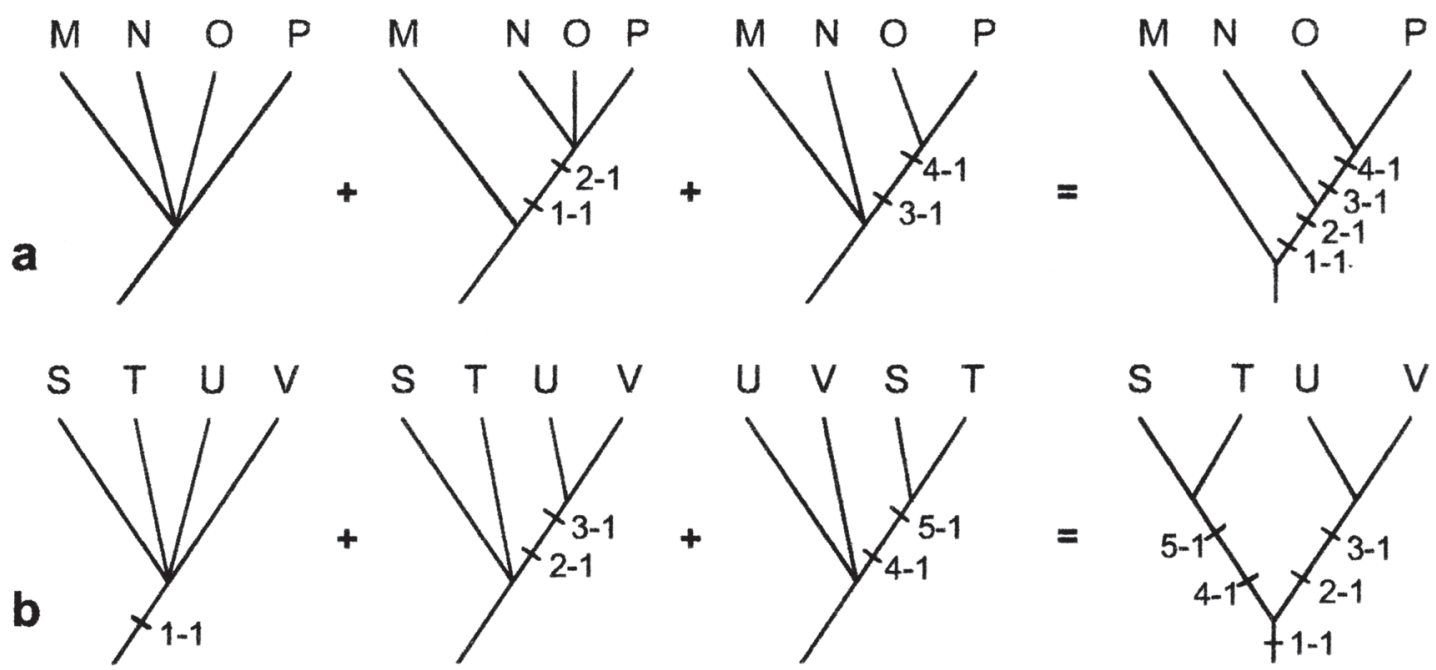

Figura 4.- (a-b) Dos ejemplos de la regla de inclusión/exclusión -o argumentación hennigiana- combinando la información de distintas series de transformación de estados de tres representaciones provisionales. Las soluciones de ambas series son los dos árboles filogenéticos respectivos de la derecha. Figura elaborada a partir de Wiley et al. (1991, Fig. 2.2.). Por ejemplo, en el caso inferior (b) se consideran cuatro taxones (S, T, U y V) y cinco caracteres (números del 1 al 5), cuya presencia se refleja con el número 1 detrás de los guiones correspondientes. La primera representación -la de la izquierda- muestra cómo el carácter 1 es común a los cuatros taxones; la segunda representación indica que los caracteres 2 y 3 sólo aparecen en los taxones U y V; la tercera muestra que los caracteres 4 y 5 están presentes en los taxones S y T. El cladorama resultante de la derecha pone en común las tres series anteriores.

basa sólo en el criterio de la similitud global para ordenar taxones, y la Cladística exclusivamente en el parentesco filogenético, la Taxonomía evolutiva argumenta que ambos criterios -similitud y genealogía- son útiles para la labor taxonómica. De ahí que la Fenética ordene los taxones bajo estudio constituyendo "grupos polifiléticos" y la Taxonomía evolutiva haga lo propio a base de "grupos parafiléticos" (Fig. 3).

En este trabajo no entraremos a comparar explícitamente y a confrontar las dos escuelas taxonómicas filogenéticas -Cladística y Taxonomía evolutiva-, cuestión que puede consultarse en el trabajo arriba citado (García Rivero 2010b), entre otras cosas porque ambas constituyen, en cierto modo, percepciones distintas y procedimientos diferentes de estudio, contando con propósitos disparejos. Mientras que la Taxonomía evolutiva contempla simultáneamente modelo y proceso, buscando y analizando elementos genealógicos en nichos ecológicos, la Cladística contempla solamente el modelo, es decir, la teoría darwinista supone el modelo desde el cual se proponen y explican los procesos (O’Brien y Lyman 2003: 96).

No obstante, sí hay que advertir que la Cladística se basa enteramente en el "principio de parsimonia" como criterio de selección entre las posibles hipótesis filogenéticas, mientras que la Taxonomía evolutiva lo hace también basándose en otros principios estadísticos como el de la "máxima verosimilitud". Frecuentemente, en los casos de estudio reales se obtiene más de una propuesta clasificatoria. Es decir, se consiguen diversas representaciones gráficas que reflejan diferentes hipótesis de cómo los taxones bajo estudio se relacionan entre sí, con base en los rasgos considerados. El criterio adoptado por la Cladística para seleccionar entre los distintos árboles es la parsimonia. Asume un devenir parsimonioso, sencillo, en los fenómenos de la Naturaleza. Ante diversas explicaciones factibles sobre un proceso o fenómeno cualquiera, la más sencilla o más fácil será seleccionada porque es la más probable (Mayr y Ashlock 1991: 216; Goloboff 2003). De esta forma, ante las diferentes hipótesis cladistas, se asumirá aquella que precise de menos cambios evolutivos. Si, así y todo, tuviésemos más de un solo cladograma de igual parsimonia -distintas representaciones de un mismo problema con igual número de cambios evolutivos-, pasaríamos a realizar un árbol de consenso (Fig. 5). En Taxonomía evolutiva, como anotábamos arriba, también se utilizan otros principios para elegir y afinar entre las diferentes representaciones gráficas, habiéndose introducido 

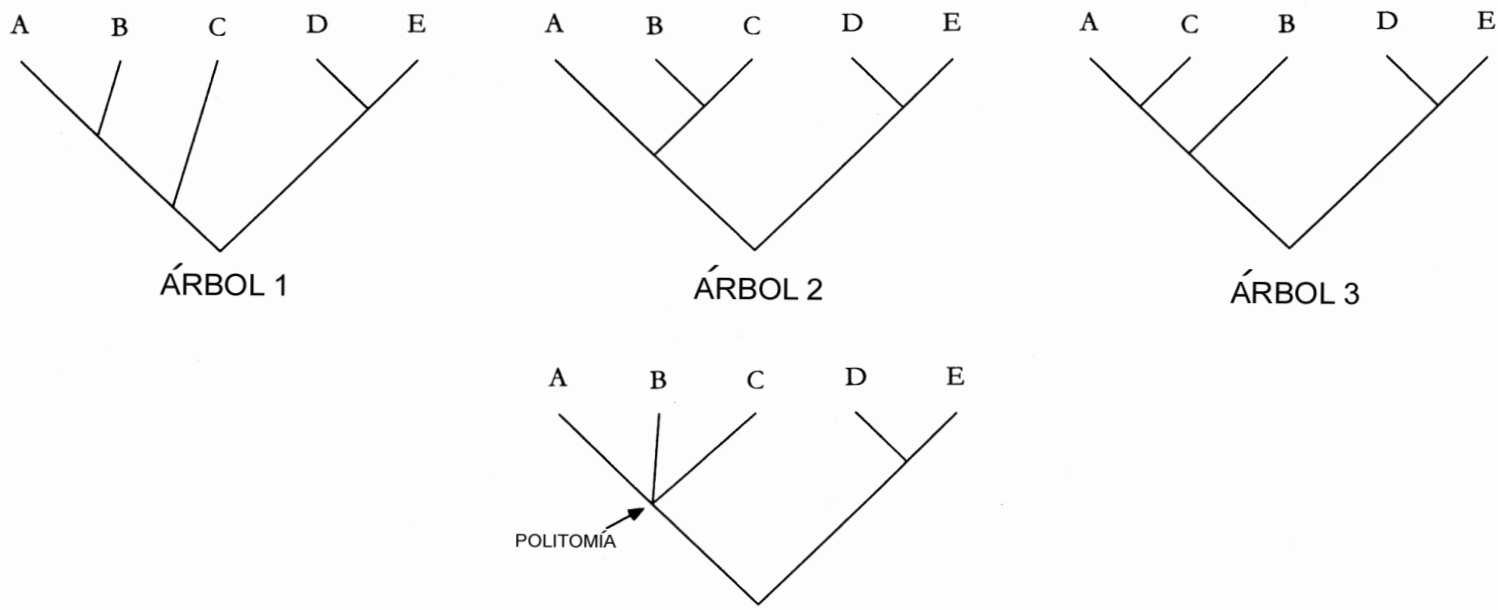

\section{ÁRBOL DE CONSENSO ESTRICTO}

Figura 5.- Situación hipotética donde existen tres posibles cladogramas de igual parsimonia que son incompatibles en cuanto al clado conformado por los especímenes A, B y C. En este caso, se practica una solución de consenso estricto - existen diversos tipos de consenso-, según la cual se conjuga toda la información de los tres cladogramas superiores en el árbol inferior. Figura elaborada a partir de O’Brien y Lyman (2003, Fig. 3.9).

hasta la actualidad el de máxima verosimilitud y el teorema de probabilidades de Bayes (e.g. Lewis 2001; Holder y Lewis 2003; Ronquist 2004). Éstos requieren, de partida, un modelo explícito de la evolución de los caracteres o parámetros. Se calcula entonces la verosimilitud para cada estado en todos los sitios, es decir, la probabilidad de los datos según el modelo. Finalmente, se selecciona el árbol filogenético con la puntuación de verosimilitud total más alta.

Antes de terminar este apartado hemos de entrar en una última cuestión, de índole técnica, que concierne a cualquier aproximación filogenética -ya sea desde la Cladística o desde la Taxonomía evolutiva. Como habíamos anotado atrás, la Filogenética se basa en la información que se transmite verticalmente, según las leyes del parentesco, o lo que es lo mismo, la información que puede explicarse según el modelo ancestro-descendiente. Frecuentemente, en fenómenos reales de la Naturaleza, los caracteres homólogos no dan cuenta de toda la información transmitida entre taxones o poblaciones. Es decir, usualmente pueden existir rasgos que no se han transmitido estrictamente mediante vía vertical, empañando así la señal filogenética que puede reconstruirse mediante estos métodos. Esta presunta deficiencia de tales técnicas responde al término técnico de "homoplasia", y puede darse por las siguientes circunstancias: 1) paralelismo o convergencia evolutiva, es decir, la emergencia independiente del mismo rasgo en taxones distintos y distantes; 2) transferencia horizontal, es decir, el traspaso de un rasgo entre taxones o poblaciones coetáneas; y 3) reversión de estados en los caracteres, es decir, la reversión espontánea de un rasgo a un estado anterior o ancestral.

Se han publicado trabajos críticos sobre la controversia del uso de métodos filogenéticos en el estudio de la evolución cultural, y más específicamente en Arqueología (e.g. Gould 1987: 70; Moore 1994; Terrell y Steward 1996; Tëmkin y Eldredge 2007; Schiffer 2008). Una de las objeciones más recurrentes y serias en dichas críticas está efectivamente relacionada con el problema de la homoplasia, habiéndose argumentado que la evolución cultural tiene una naturaleza distinta de la orgánica, ya que aquélla es altamente reticulada (cf. O'Brien et al. 2008: 48). Esta discusión sobre la dicotomía de ambos modelos no es reciente (e.g. Bellwood 1996) y ha provocado incluso que últimamente algunos trabajos hayan evaluado la importancia de la phylogenesis frente a la ethnogenesis en casos antropológicos y arqueológicos reales (e.g. Collard y Tehrani 2005; Collard, Shennan y Tehrani 2006).

En cualquier caso, este presunto problema no es exclusivo de la aplicación filogenética al estudio de la cultura (cultura material inclusive). Los biólogos moleculares y todos los dedicados al estudio de microorganismos se enfrentan diariamente con esta dificultad. Desde hace algunos años se viene conociendo la importancia de la transmisión horizontal entre genomas de bacterias (Margulis y Sagan 2002). Pero también cuentan con altas tasas de 
transmisión horizontal, bien constatada, muchos géneros y familias de animales y de vegetales. Como M. J. O'Brien y R. L. Lyman han recordado - citando los estudios correspondientes- (cf. 2003: 104-105), incluso la hibridación parece estar bien documentada en la evolución biológica, como por ejemplo en el reino de las plantas, donde puede alcanzar índices de hasta el 20\%, especialmente en las angiospermas; y, con valores algo más reducidos, se constata también en el reino animal, donde podrían destacarse entre otros los pájaros (Laskowski y Fitch 1989).

Algunos trabajos han contrastado estas técnicas mediante la evaluación del impacto de híbridos y la influencia de la homoplasia en los índices y coeficientes actualmente utilizados en Cladística (Sanderson y Donoghue 1989; McDade 1992; Baroni, Semple y Steel 2004; 2006; Greenhill, Currie y Gray 2009; Muscio 2010), y, aunque los problemas no son tan pronunciados, probablemente existan algunas flaquezas que deberían estudiarse para solventar dichos escollos. Sin embargo, la constatación de transmisión horizontal entre poblaciones de microorganismos, especies vegetales y animales no ha llevado al rechazo de los análisis filogenéticos en Biología (cf. O’Brien et al. 2008: 48). ¿Puede imaginarse ésta sin métodos filogenéticos? Aun cuando se reconozca alguna tasa de transferencia horizontal de información genética, o incluso de la existencia de híbridos, los biólogos no ignoran estos métodos porque saben que permiten reconstrucciones taxonómicas más fidedignas y científicas que cualquier otra aproximación disponible hoy en día.

Por tanto, la cuestión de la transmisión horizontal y de la homoplasia es un problema metodológico -más que teórico (Bellwood 1996)- al que podría hacerse frente mediante el estudio y depuración de las propias técnicas filogenéticas. La subestimación de procesos de anagénesis e hibridación fue afrontada hace tiempo por J. S. Farris, quien intentó resolver dicho problema mediante la computación de árboles de Wagner y la construcción de redes (Farris 1970). Más recientemente, algunos autores empiezan a presentar modelos alternativos para contrarrestar el efecto de la homoplasia y de la transferencia horizontal (así como la existencia de politomías ${ }^{9}$ en los internodos), proponiendo técnicas basadas en "redes" o networks con diversos métodos como Split decomposition y Neighbor Net (Bryant y Moulton 2002; Makarenkov y Legendre 2004; Bryant, Filimon y Gray 2005), o en "análisis de reconciliación" y "modelos bayesianos mixtos" (Gray, Greenhill y Ross 2007), y también lo que se ha denominado rings of life (Rivera y Lake 2004).

\section{Estudios filogenéticos culturales}

En este apartado nos disponemos a exponer un resumen de los estudios que han considerado de alguna forma una concepción evolutiva del cambio cultural $\mathrm{y}$, sobre todo, de aquellos más recientes que vienen aplicando técnicas y métodos analíticos sistemáticos para rastrearlo. Aunque haremos referencia a algunos trabajos pioneros en estas aplicaciones, procedentes de diversas áreas de conocimiento de las ciencias sociales como la Lingüística y la Antropología, nuestro objetivo básico será mostrar la historia de estas aplicaciones en el campo específico de la Arqueología.

Incluso antes que los naturalistas, algunos lingüistas intuyeron que los idiomas históricos debían de proceder de otras lenguas ancestrales, y por tanto que estaban sujetos de alguna forma a un proceso de evolución modificada en el sentido que posteriormente propondrían Lamarck o Darwin (con las consabidas diferencias entre ambos). El primer exponente del que tenemos constancia a este respecto es el holandés M. Z. van Boxhorn, quien sospechó que la similitud entre las lenguas indoeuropeas podría deberse a la existencia de una primitiva lengua común denominada "escita"; él no se limitó a una comparación léxica entre lenguajes, sino que consideró la comparación de todas las lenguas "como sistemas orgánicos de regularidades gramaticales", lo que le llevó en 1643 a reconocer la familia indoeuropea (van Driem 2001: 159).

Sin duda, hay que mencionar también el trabajo de W. Jones (1786), que continuó con esta idea y sugirió que la gran similitud entre el sánscrito y los idiomas europeos, como el griego y el latín, no podía deberse a la casualidad. Más bien tuvieron que haber emergido de una única lengua ancestral no muy antigua conocida ahora como Protoindoeuropeo. La gente que la habló se habría difundido a través de Eurasia, y distintas poblaciones habrían quedado aisladas conformando diversas comunidades lingüísticas $\mathrm{y}$, con el paso de las generaciones, idiomas diferentes.

Apenas transcurrido un lustro desde que viera la luz la primera edición del Origen de las especies, se publicó una propuesta genealógica sobre las lenguas indoeuropeas por parte de A. Schleicher (1863). Como su propio título indica, esta obra estaba ya fuertemente influida por el trabajo fundamental de Darwin, entonces recién publicado. Por ello, no sorprende que en la obra de A. Schleicher encontremos una clasificación de la evolución de algunos idiomas indoeuropeos al puro estilo de las representaciones gráficas filogenéticas actuales (Fig. 6).

Esta concepción evolutiva en el campo lingüístico no se limitó al estudio de la evolución de los 


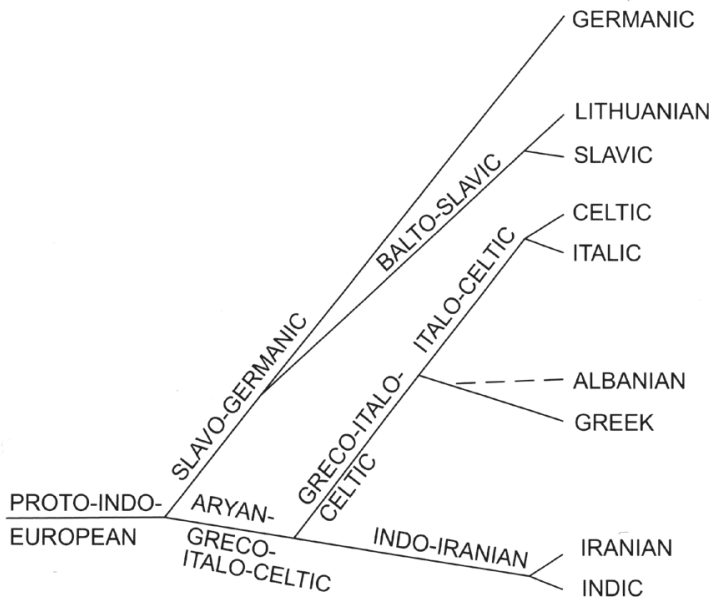

Figura 6.- Árbol filogenético (basado en el parentesco) como modelo de la evolución de las lenguas indoeuropeas según Schleicher (1863, tomado de Forster y Renfrew 2006, Fig. I.2.).

lenguajes. La idea de que el estudio sistemático de las variantes (elementos cambiantes) en las tradiciones de manuscritos es de naturaleza genealógica es lo que reclamaron desde la primera mitad del siglo XIX los estudiantes y analistas de manuscritos -área denominada en español Ecdótica-, como K. Lachmann y C. Gottlieb Zumpt. Existen algunos trabajos más recientes en esta área de conocimiento que estudia las tradiciones de manuscritos (cf. Spencer et al. 2006: 67; Lipo et al. 2006b: 5).

Durante el siglo XX, y sobre todo en estos últimos años, también se han desarrollado estudios lingüísticos mediante enfoques y métodos propiamente filogenéticos -algunos más puramente cladísticos y otros usando simultáneamente herencia y distancia- (e.g. Renfrew 1992; Gray y Jordan 2000; Holden 2006; Gray y Atkinson 2003; Rexová, Frynta y Zrzavy 2003; Greenhill y Gray 2005; Holden, Meade y Pagel 2005; Bryant, Filimon y Gray 2005; Forster y Renfrew 2006; Atkinson y Gray 2006).

En cuanto a Antropología y Arqueología se refiere, los trabajos pioneros sobre evolución cultural proceden de las academias norteamericana y europeas en el siglo XIX, cuando compartían modelos unilineales y progresivos que consideraban el cambio cultural como procesos dirigidos desde fases rudas (sociedades salvajes o bárbaras) hacia estados más perfectos o elaborados (civilizaciones), $\mathrm{y}$ donde el factor de la necesidad humana era el propio motor de la evolución. Valga citar los conocidos trabajos de E. B. Tylor (1871) y L. H. Morgan (1877).
Los primeros 60 años del siglo $\mathrm{XX}$ cuentan con otros modelos de evolución cultural (cf. O'Brien y Lyman 2003: 3; y Steward 1955; White 1959; Service 1962) basados en la idea de la descendencia con modificación darwiniana, aunque la fuerza del cambio seguía siendo prácticamente la misma (necesidad e intencionalidad humanas) que en los modelos anteriores. No se atendió a métodos que profundizasen en cómo y por qué se producían las determinadas evoluciones y tradiciones culturales. Sólo se anotaba de forma metafórica, y nunca analítica, que los factores de invención independiente y de préstamos culturales (difusión) explicarían todos los procesos (cf. O’Brien y Lyman 2003: 4).

Las técnicas y métodos empleados en esta primera etapa del análisis de la evolución cultural, expresamente la de naturaleza material, tenían como objetivo simplemente crear clasificaciones o líneas que relacionasen objetos arqueológicos a lo largo del tiempo. Entre estas técnicas se encuentra la "seriación", basada en la asunción de la continuidad histórica $-\mathrm{y}$, en algún sentido, de la herencia-, y que construye series de materiales ordenadas cronológicamente. Asume que el grado de similitud entre dos objetos se relaciona directamente con el grado de proximidad en el tiempo.

Los especialistas en la materia M. J. O’Brien y R. $\mathrm{L}$. Lyman han recogido en algunas de sus publicaciones (O’Brien y Lyman 1999; 2003; Lyman y O'Brien 2006) los hitos fundamentales de la historiografía de esta técnica. Los trabajos de mediados del siglo XIX de J. Evans sobre monedas británicas protohistóricas y romanas son probablemente uno de los primeros ejemplos al respecto (Fig. 7: 3a). También A. H. Pitt Rivers, en 1875, publicó series de artefactos arqueológicos y etnográficos procedentes de culturas melanesias, como las de palas de remos de Nueva Irlanda en el archipiélago de Bismarck (Fig. 7: 1a). En 1899, W. M. F. Petrie ordenó conjuntos de artefactos encontrados en tumbas egipcias antiguas, concretamente en este caso recipientes cerámicos (Fig. 7: 3b). En 1915, B. Dean trató la evolución de cascos metálicos de épocas medieval y moderna (Fig. 7, 2a), y realizó otras seriaciones divergentes sobre diversos tipos de espadas, pero éstas no fueron publicadas entonces (cf. Lyman y O’Brien 2006, Figs. 5.12., 5.13. y 5.14.). En 1917, A. V. Kidder también utilizó la técnica de seriación para la clasificación de las cerámicas de Pecos Pueblo, en Nuevo México (Fig. 7: 1b). Algunos años después, en 1937, E. B. Sayles ordenaría elementos conocidos como "manos" y "metates" (molederas y morteros) procedentes de Snaketown, Arizona (Fig. 7: 2b). También en 1937, H. S. Colton y L. L. Hargrave (1937) entendieron de esta forma la clasificación de las series y tipos cerámicos del $\mathrm{Su}-$ roeste norteamericano (Fig. 7: 2c). 

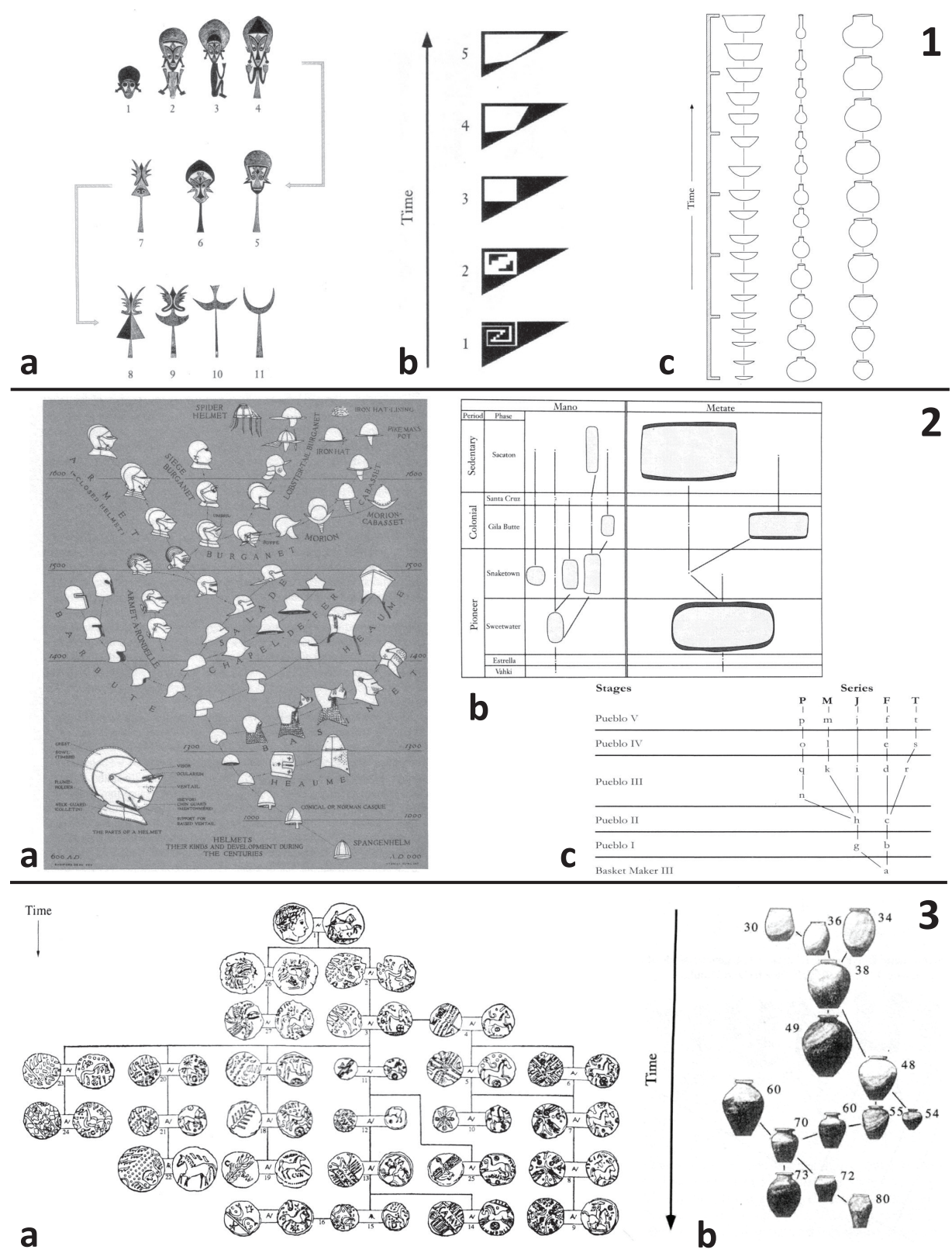

Figura 7.- .1) Ejemplos de secuencias arqueológicas basadas en el modelo de evolución anagenética: 1a) Seriación de canaletes del archipiélago Bismarck, Nueva Guinea, por Pitt Rivers en 1875 (Lyman y O'Brien 2006, Fig. 5.3.); 1b) Seriación de motivos decorativos en cerámica de Pecos Pueblo, Nuevo Méjico, según Kidder en 1917 (Lyman y O’Brien 2006, Fig. 5.1.); 1c) Seriación de artefactos materiales concebida por J.A. Ford en 1962 (O’Brien y Lyman 2003, Fig. 1.1.); 2) Ejemplos de secuencias arqueológicas basadas en el modelo cladogenético: 2a) Evolución genealógica de los cascos metálicos medievales y modernos según Dean en 1915 (Lyman y O’Brien 2006, Fig. 5.10.); 2b) Propuesta de desarrollo de moletas y molinos de Snaketown, Arizona, según Sayles en 1937 (Lipo et al. 2006b, Fig. 1.2.); 2c) Representación hipotética de las relaciones entre las series de cerámicas (letras mayúsculas) y sus tipos (minúsculas) del Suroeste norteamericano según Colton y Hargrave en 1937 (O’Brien y Lyman 2003, Fig. 1.5.); 3) Ejemplos de secuencias arqueológicas basadas en los modelos evolutivos de anagénesis, de cladogénesis y de reticulación: 3a) Seriación de monedas romanas británicas según Evans en 1850 (O’Brien y Lyman 2000, Fig. 6.6); 3b) Genealogía de cerámicas de tumbas predinásticas egipcias según Petrie en 1899 (Lyman y O’Brien 2006, Fig. 5.6.). 
Hay que distinguir, no obstante, distintos tipos de seriaciones entre los ejemplos del párrafo anterior. Se tratan de diferentes concepciones de la ordenación en función del modelo evolutivo concebido (anagénesis, cladogénesis o reticulación). El primero de ellos -el basado en la anagénesis- concibe un cambio gradual unilineal, es decir, diferentes taxones van sucediéndose y sustituyéndose entre sí en una única línea vertical (O’Brien y Lyman 1999). Algunos de los trabajos anteriores (Fig. 7: 1) utilizaron exclusivamente este tipo de seriación -también llamada filética-, como los de Pitt Rivers y Kidder, y también fue concebido por A. Ford en sus discusiones teóricas de 1962 (cf. O’Brien y Lyman 2003: 7). El segundo -el basado en la cladogénesis- fue implementado por Sayles y por Colton y Hargrave (Fig. 2b y c). Se fundamenta en la idea según la cual desde un taxón ancestral descienden dos nuevos taxones, siendo en efecto el modelo en el que se basaría la Sistemática filogenética o Cladística. Dean aplicó conjuntamente este modelo con el anagenético (Fig. 7: 2a). El tercer modelo - el de la reticulación- se basa en la idea de que dos taxones pueden hibridar hasta el punto de dar lugar a un nuevo tercer taxón. Dicho modelo fue usado, conjuntamente con los dos anteriores, por Evans y Petrie (Fig. 7: 3).

Además, existen algunas variantes de estas seriaciones que reflejan otra clase de información, no sobre el desarrollo individual de los taxones sino sobre los conjuntos arqueológicos. El trabajo de A. L. Kroeber en 1916 sobre conjuntos cerámicos del Pueblo Zuñi en Nuevo México, según cuatro formas establecidas de recipientes, se constituye como el primer ejemplo de "seriación de frecuencias" (cf. O'Brien y Lyman 2003: 11-12). También se ha diferenciado la "seriación de ocurrencia", la cual se estableció a partir de la mitad del siglo XX (cf. Lyman y O'Brien 2006: 71). Mientras que la seriación de frecuencia se basa en la cantidad relativa de los presuntos tipos históricos, usualmente medida en porcentaje, la de ocurrencia se basa en la presencia o ausencia de aquéllos. Ambas seriaciones, igual que todas las anteriores, asumen la inferencia de información cronológica basada en la continuidad histórica ${ }^{10}$.

En definitiva, ha habido numerosos trabajos arqueológicos y antropológicos que, de alguna forma, adoptaron desde antiguo ideas y técnicas referidas a la continuidad histórica - de la continuidad heredable- y a la reconstrucción de seriaciones presuntamente ordenadas cronológicamente. Sin embargo, debemos anotar un par de objeciones importantes en contra de esta primera fase evolucionista. Por un lado, hemos de insistir en que estas aproximaciones estaban generalmente desprovistas de una teoría ex- plicativa -o explícitamente asociada con el fenómeno estudiado- acerca del cambio cultural. Por ello, la mayoría de los autores citados desarrollaron estas formas de ordenaciones aun sin preguntarse sobre la propia naturaleza de la información cultural que se transfería a lo largo del tiempo y que quedaba materializada en sus artefactos de estudio, así como tampoco sobre de qué maneras (por cuáles mecanismos) se había transmitido dicha información. Por otro lado, una característica compartida por todas estas seriaciones es que se construyeron según el criterio de la similitud entre objetos, por ejemplo la forma de los mismos o el tipo de decoración que exhibían, y no se basaron en homologías derivadas compartidas como actualmente hace la Cladística.

A partir de los años 60 del siglo XX los estudios antropológicos y arqueológicos olvidaron las cuestiones sobre filogenias culturales y pusieron sus esfuerzos en aspectos de otra índole, generalmente funcionalista, bajo el prisma del Procesualismo. Aunque esta corriente académica sigue vigente, fue a partir de los años 80 cuando de nuevo se retomaron los intereses por la búsqueda de filogenias culturales. Esta nueva etapa sucede por tanto a la corriente procesualista, de la que es de alguna forma deudora ya que en ésta se habían invertido grandes esfuerzos destinados a la sistematización y a la construcción de modelos de los fenómenos estudiados en las aproximaciones arqueológicas y antropológicas. La aplicación de la componente matemática y estadística, que cubre las necesidades metodológicas de modelización, se desarrolló por tanto durante la Nueva Arqueología procesualista, $\mathrm{y}$ es en parte una base subyacente que ha facilitado la incorporación de las técnicas y métodos filogenéticos a nuestra área de conocimiento. Por supuesto, en esto ha influido también de forma relevante el avance que en ese momento tuvieron los medios informáticos para realizar cálculos con grandes cantidades de datos.

Las flaquezas anotadas antes sobre la primera fase evolucionista comenzaron a salvarse en esta fase, a partir de finales de los 70 y 80 del siglo pasado. Desde entonces, en Antropología se ha venido haciendo un considerable trabajo para entender los procesos de transmisión cultural (e.g. Durham 1976; 1991; Pulliam y Dunford 1980; CavalliSforza y Feldman 1981; Boyd y Richerson 1982; 1985; Richerson y Boyd 2005). También entonces se reabrió el debate teórico sobre la aplicación general de la teoría darwinista en Arqueología (e.g. Dunnell 1978; 1980; Teltser 1995; Maschner 1996; O’Brien 1996; Barton y Clark 1997; O’Brien y Lyman 2000; Hart y Terrell 2002; Shennan 2002). Fue además entonces, con base en la información de la que disponemos, cuando se realiza la primera 
aplicación cladística (moderna) a materiales arqueológicos, concretamente a esculturas ibéricas y a fíbulas de La Tène, a manos de T. Chapa (1980; 1984). Estos trabajos procedentes de la academia española quedaron aislados, y esta línea de investigación no llegó nunca a desarrollarse ni siquiera por su propia autora.

La última fase de la aplicación de los métodos filogenéticos a la Arqueología, tal y como la entendemos actualmente, se puede situar desde hace solamente una década, cuando se reflexionan y desglosan en detalle los puntos principales de esta metodología en relación a su área específica (cf. O’Brien y Lyman 2000). Esta etapa actual ha renacido con más fuerza en las academias norteamericana y británica fundamentalmente. Prueba de ello y, sobre todo, del ímpetu actual de la Filogenética cultural, ahora sistemática, son las recientes ediciones de diversos trabajos que recopilan contribuciones muy variadas en técnicas, métodos y contenidos (Mace, Holden y Shennan 2005; Forster y Renfrew 2006; Lipo et al. 2006; O'Brien 2008; Shennan 2009). No obstante, en países de lengua castellana también se han elaborado diversos trabajos monográficos sobre esta línea de investigación de las filogenias arqueológicas (García Rivero 2010a; Escacena, García Rivero y García Fernández 2010).

Además de estas obras monográficas, se ha producido durante estos últimos años un volumen importante de estudios y aplicaciones de estos métodos filogenéticos en publicaciones de naturalezas y alcances diversos. Algunos de los especialistas más reconocidos de esta línea de investigación han anotado -refiriendo los trabajos correspondientes(cf. O’Brien et al. 2008: 40) que los estudios filogenéticos realizados en Antropología y Arqueología en las dos últimas décadas se podrían clasificar en tres categorías: 1) trabajos que trazan líneas de transmisión y descendencia hacia atrás en el tiempo hasta llegar a ancestros comunes (prototipos), y luego examinan los procesos que subyacen sobre la distribución geográfica y el desarrollo cultural de los descendientes; 2) estudios que primero crean grupos anidados de taxones relacionados, denominados clados, y luego rastrean dichos taxones geográficamente; y 3) estudios comparativos que dependen del entendimiento de modelos de descendencia para examinar la distribución de los rasgos funcionalmente adaptativos.

Estos trabajos, que vienen aplicando sistemáticamente métodos filogenéticos en áreas de conocimientos concernientes a la evolución cultural humana, tratan diversos ámbitos geográficos a lo largo de la Tierra, así como un rango cronológico bastante dilatado. Respecto a la geografía del registro estudiado, como ya han recogido algunos especialistas (cf. Lipo et al. 2006b: 5), se han hecho aproximaciones en Europa, Asia, África, Norteamérica y el Pacífico.

En los que se ha estudiado la cultura material, existen aproximaciones filogenéticas concretas y algunas otras más centradas en los propios procesos de transmisión cultural. Además de los recogidos en el trabajo anterior (cf. Lipo et al. 2006b: 5-6), existen otros trabajos sobre industria lítica (Darwent y O'Brien 2006; Eerkens, Bettinger y McElreath 2006; Apel y Darmark 2007; Buchanan y Collard 2008), sobre figuras simbólicas pétreas (García Rivero 2010a), sobre industria ósea (Riede 2008), sobre cerámica (Cochrane 2004; 2008; Harmon et al. 2006; Neff 2006), sobre elementos decorativos en soportes varios (VanPool, Palmer y VanPool 2008), sobre instrumentos musicales (Tëmkin y Eldredge 2007) y también en estudios multidisciplinares (Moylan et al. 2006) ${ }^{11}$.

\section{Discusión}

La aplicación de la Teoría de la evolución darwiniana a la Arqueología no cuenta apenas con tradición alguna en la academia española, y aquellos escasos que dicen aceptarla, fundamentalmente especialistas sobre homínidos del Pleistoceno, solamente lo hacen a medias, dado que la asumen sólo para la evolución biológica de los cuerpos pero no para sus pautas de comportamiento y sus manifestaciones culturales, mucho menos si son éstas las de Homo sapiens (Escacena 2010).

La Arqueología española, y extensiblemente la mayor parte de la academia europea, tampoco cuenta con mucha tradición en la discusión teórica de la Taxonomía si la comparamos con la academia norteamericana, $\mathrm{y}$, aun existiendo un arraigado hábito en cuanto a la propia tarea de clasificar, los enfoques y métodos utilizados han sido y -todavía hoy- son sumamente sesgados y parciales. La mayoría de los arqueólogos europeos y especialmente españoles se ha molestado en anotar y describir todos y cada uno de los caracteres considerados en sus estudios, pero sus esfuerzos a este respecto no han pasado de la tarea descriptiva de los objetos pertinentes, y han sido poquísimos los investigadores que han usado dichos rasgos de una forma analítica. Es decir, los atributos de estudio, que deben ser teóricamente pilar central en la creación de tipos, apenas se han trabajado de forma operativa. Y todo ello debido a la falta de un cuerpo teórico subyacente que permita una vinculación metodológica apropiada y eficaz con los caracteres y datos de estudio, y también por la existencia exclusiva 
de un concepto de especie tipológico-fenético sin la consideración al menos teórica de otros conceptos y métodos taxonómicos.

La escasa tradición en el estudio de las cuestiones taxonómicas de las academias española y europea, además de lo recién dicho, también cuenta con otro factor explicativo que ha influido en los hábitos de esta trayectoria -replicada a lo largo de estas generaciones más por inercia irreflexiva o por tradición de hacer las cosas que por otra razónhasta el punto de poder llegar a exculparse. La Arqueología norteamericana se topó frecuentemente desde sus inicios con un registro arqueológico descontextualizado, donde las más de las veces los objetos estudiados no contaban con información externa referente a su estratigrafía y tampoco con cronologías absolutas. En esta situación, las discusiones que abordaban toda esta problemática y profundizaban en el estudio taxonómico arqueológico constituyeron obras fundamentales y referentes básicos, de modo que dicha tradición se reprodujo exitosamente a lo largo del siglo $\mathrm{XX}$. En cambio, la Arqueología del Viejo Mundo contaba ciertamente con un registro arqueológico más sustancial. Aunque fuese solamente de manera parcial, centrada en algunos de los yacimientos más conocidos entonces, se disponía de más información contextual desde momentos tempranos. Se introdujese antes o después entre las academias europeas la noción estratigráfica más o menos actual, ciertamente se partió de unas circunstancias distintas de trabajo, lo que provocó que ambos círculos académicos mantuviesen vigentes y fluyentes algunas diferencias. A partir de mediados del siglo XX se contaba con cierto dominio de las leyes de la estratigrafía (incluso mucho antes en un marco académico más general: recuérdense las fases de Troya conocidas a finales del siglo XIX), si bien dicho conocimiento se consolidó notablemente a finales de la década de los 70 del siglo pasado (aparentemente correlacionado con el impulso autoctonista liderado por Renfrew en un contexto político europeo bien distinto del que le precede). Por entonces, y esto es una variable de peso, también se depuraron las técnicas analíticas de lo que llamamos datación absoluta. En fin, que con la ayuda y asistencia de estratigrafías y fechas absolutas, hemos desechado -hoy prácticamente olvidado- aquellas técnicas que permiten ordenar intrínsecamente una serie de objetos; esas que constituyen un procedimiento metodológico sustentado en el análisis riguroso y sistemático de los propios rasgos y objetos basadas en la continuidad -heredable- histórica y que empezaron a desarrollarse hace ya bastante tiempo -y fueron más o menos comunes- en el ámbito norteamericano.
Con esto no se pretende ni mucho menos desacreditar la importancia de las estratigrafías y técnicas de datación absoluta, tan importantes ambas en nuestra ciencia, sino advertir del potencial de éstas si se ponen en conjunto con técnicas taxonómicas intrínsecas basadas en esa continuidad histórica y en el principio de parentesco. La integración conjunta de todas ellas se convierte así en un resorte fundamental muy apropiado para el análisis secuencial y el planteamiento de hipótesis de contingencia histórica.

$\mathrm{Y}$ es que hay que recalcar el potencial metodológico e interpretativo que la Filogenética puede aportar a la Arqueología, potencial éste con carácter fértil (incrementa notablemente la exposición de hipótesis de contingencia histórica) y experimental (posibilita la comprobación de las mismas). Resumidamente, el gran potencial de la Cladística estriba en: 1) la alineación epistémica con el modelo taxonómico linneano y la teoría evolutiva por descendencia modificada-verdades o hechos éstos demostrados-; 2) la aplicación sistemática de unos principios claramente objetivos y coherentes, esto es, el establecimiento de relaciones filogenéticas o de parentesco mediante la agrupación anidada de taxones según la existencia de caracteres derivados compartidos; 3) la posibilidad de contraste y refutación, o criterio popperiano de falsabilidad; $\mathrm{y}$, derivado del anterior, 4) la valoración objetiva y sistemática de hipótesis y resultados a través de una base estadística que reduce la incertidumbre y ambigüedad presentes en otros métodos y modelos arqueológicos.

El potencial y las ventajas de la metodología filogenética para la Arqueología no deben descartarse pues a la ligera, porque las (confusas) críticas vertidas sobre tal aplicación apenas se sostienen. De entre ellas, la única que parcialmente constituye una objeción fundamentada, tal y como hemos expuesto al final del apartado cuatro $-\mathrm{y}$ por ello no redundaremos en esta cuestión-, es la del problema de la transmisión horizontal y la homoplasia. De todas formas, un punto importante en su defensa -para responder a dicha crítica- es que el propio método cladístico, tal y como se entiende y utiliza actualmente incluso en su versión más sencilla, sirve para evaluar o diagnosticar los posibles modelos de transmisión de la información. Es decir, si nuestros resultados indicasen un exceso de ruido filogenético, estaríamos teniendo indicios de mecanismos por los cuales algún tipo de homoplasia acontece, y por tanto podríamos incluso preguntar y considerar la intensidad de los diferentes mecanismos de transmisión que afectan de un modo u otro a los conjuntos coherentes de la cultura (Jordan y Mace 2006: 151). No obstante, ya aclaramos atrás que tal 
presunta flaqueza no se trata de un asunto filosófico o teórico sino exclusivamente metodológico.

Por tanto, lo que puede hacerse en adelante es depurar la propia metodología filogenética e integrar conjuntamente tanto las distintas técnicas existentes desde hace tiempo como las que se vienen desarrollando recientemente. De hecho, y como también anotábamos atrás, la propia metodología está experimentando un desarrollo muy notable en estos últimos años. Claro que éste se viene produciendo fundamentalmente en campos de conocimientos ajenos, o más bien vecinos, como la Biología evolutiva (y específicamente la Biología molecular) donde estos métodos se utilizan asiduamente (e.g. Yang y Goldman 2008). No obstante, y aunque la aplicación filogenética sistemática en Arqueología sea muy reciente, algunos de los especialistas más reconocidos en este campo ya han advertido que efectivamente los métodos filogenéticos de parsimonia y de máxima verosimilitud habrían de acompañarse con otras técnicas, tales como la simulación, los gráficos de descomposición y análisis de redes, el test de independencia serial, la parsimonia iterada, los métodos bayesianos como las cadenas de Monte Carlo, los test de matriz de correspondencia, la evaluación de la estructura jerárquica de los grupos y la seriación (O’Brien et al. 2008: 58). Seguramente el esfuerzo merezca la pena.

\section{Agradecimientos}

Quisiera agradecer por escrito a Ruth Taylor y a mis colegas José Luis Escacena Carrasco, Enrique García Vargas y Manuel J. Casado Ariza el tiempo y ayuda que me han prestado. Los cuatro leyeron el borrador de este artículo e hicieron comentarios interesantes que mejoraron la versión definitiva. Ruth, además, tradujo al inglés el resumen y las palabras claves.

\section{Notas}

1. Trabajo elaborado en el marco del grupo de investigación HUM-402 del Plan Andaluz de Investigación.

2. J. Diamond (2008: 275-303) recoge diversos casos referentes a la evolución de la tecnología humana para demostrar esto. Por ejemplo, T. Edison protestó inicialmente cuando su invento del fonógrafo se aplicó (degradando las serias posibilidades de éste) a la reproducción de música en gramolas tragaperras. Su invento no tuvo éxito en ninguna de las diez posibles aplicaciones que él mismo había intencionalmente pensado y previsto. También es ilustrativo a este respecto el ejemplo de la "invención" del vehículo de motor. Aunque el primer motor de combustión interna se construye en 1866, y se instala en un vehículo de cuatro ruedas en 1896, no fue hasta la Primera Guerra Mundial cuando se acepta su uso en camiones y otros vehículos, sustituyendo éstos poco a poco, durante los siguientes cincuenta años, al uso exclusivo de caballos y ferrocarriles.

3. F. Galton, primo de Darwin, refirió este aspecto en el terrero de la Antropología, y anotó que los estudios comparativos de adaptación humana eran irrelevantes si no se descartaba la posibilidad de que las diversas culturas hubiesen compartido un origen común del rasgo adaptativo bajo estudio (O’Brien et al. 2008: 39). Esta cuestión es conocida en el mundo académico como el "problema de Galton".

4. Más adelante, en la primera parte del apartado 5, haremos un repaso a algunos de los estudios antropológicos de los siglos XIX y XX que ejemplifican mejor los diversos métodos de secuenciación.

5. Actualmente, junto a la "Cladística" existe otra escuela taxonómica denominada "Taxonomía evolutiva", que definiremos brevemente un poco más adelante. Ambas escuelas -Cladística y Taxonomía evolutiva- conforman lo que hoy se conoce como "Filogenética" o metodología filogenética.

6. Esto no quiere decir, en absoluto, que la historiografía no cuente con estudios que hayan considerado la idea de la evolución para la clasificación de la documentación antropológica y arqueológica. Numerosas secuencias y seriaciones antiguas de dichos registros, por ejemplo en el Historicismo Cultural, estaban basadas en una idea de la evolución por descendencia modificada, aunque fuese vaga y desprovista de métodos explícitos y efectivos para la explicación del cambio cultural. Una síntesis de la historiografía sobre los estudios culturales que han considerado de alguna forma la idea de la evolución se desarrollará en el apartado 5.

7. Si la transmisión genética tiene lugar mediante la replicación y traspaso de la información contenida en el genoma, la transmisión cultural puede operar por diversos mecanismos, tales como la observación, la emulación, la imitación, el estímulo condicionado, la enseñanza directa, el lenguaje hablado y la escritura, etc., en una variedad de procesos más o menos complejos (Richerson y Boyd 2005: 63). 
8. El término "cladograma" se utiliza por parte de los cladistas para referir la representación gráfica de un diagrama de ramas especificando una hipótesis de relaciones jerárquicas entre los taxones con base en caracteres derivados compartidos. Una vez un cladograma es enraizado -precisando y asumiendo un ancestro común concreto en la base de la representación, así como por tanto una polaridad temporal determinada- pasa a constituir un "árbol filogenético".

9. Se denomina con el nombre técnico de "politomía" al internodo de un cladograma (hipotético taxón ancestral) que agrupa conjuntamente a más de dos taxones (cf. Fig. 5).

10. Posteriormente se han desarrollado por supuesto numerosas técnicas de seriación fundamentadas por ejemplo en ordenaciones multivariantes (e.g. Doran y Hodson 1975; Fernández Martínez 1985) pero esto se aleja de la temática principal (evolución y filogenias) y de la línea de exposición historiográfica de este trabajo.

11. Si entendemos el cultivo y la agricultura como un tipo de adaptación cultural humana o, más bien, como una coevolución entre grupos humanos y determinadas especies vegetales dentro de las redes simbióticas (Rindos 1980; 1990), también podemos mencionar algunos análisis filogenéticos realizados sobre cuestiones de esta clase (e.g. Coward et al. 2008).

\section{REFERENCIAS BIBLIOGRÁFICAS}

Apel, J.; Darmark, K. (2007): Den flathuggna pilspetsens fylogeni. Mellansvenskt stenhantverk ur ett kulturevolutionistiskt perspektiv. Stenålder i Uppland. Uppdragsarkeologi och eftertanke (N. Stenbäck, ed.), Arkeologi E4, Uppsala: 31-65.

AtKInSOn, Q.D.; Gray, R.D. (2006): Are accurate dates an intractable problem for Historical Linguistics? En Lipo et al. 2006: 269-296.

Baroni, M.; Semple, C.; Steel, M. (2004): A framework for representing reticulate evolution. Annals of Combinatorics, 8: 391-408.

(2006): Hybrids in real time. Systematic Biology, 55 (1): 46-56.

Barton, C.M.; Clark, G.A. (1997) (eds.): Rediscovering Darwin: Evolutionary theory and archeological explanation. Archeological papers of the American Anthropological Association, 7.

Bellwood, P. (1996): Phylogeny vs reticulation in Prehistory. Antiquity, 70: 881-890.

Bentley, R.A.; Lipo, C.; Maschner, H.D.G.; Marler, B. (2008): Darwinian archaeologies. Handbook of archaeological theories (A. Bentley, H.D.G. Maschner y C. Chippindale, eds.), Altamira Press, Lanham: 109-132.

Boyd, R.; Richerson, J.R. (1982): Cultural transmission and the evolution of cooperative behaviour. Human Ecology, 10: 325-351.

(1985): Culture and the evolutionary process. Chicago University Press, Chicago.

Breull, H. (1935): Les peintures rupestres schématiques de la Péninsule Ibérique. Imprimerie de Laquy, Lagnysur-Marne.

Bryant, D.; Filimon, F.; Gray, R.D. (2005): Untangling our past: Languages, trees, splits and networks. En Mace et al. 2005: 67-84.

Bryant, D.; Moulton, V. (2002): NeighborNet: An agglomerative method for the construction of planar phylogenetic networks. Workshop in algorithms for Bioinformatics, Proceedings of the second international workshop in Rome - Lecture notes in computer science (R. Guigó y D. Gusfield, eds.), Springer, Berlin y New York: 375-391.

Buchanan, B.; Collard, M. (2008): Testing models of early paleoindian colonization and adaptation using Cladistics. En O'Brien 2008: 59-76.

CARPENTER, E.; SCHUSter, C. (1988): Materials for the study of social symbolism in ancient and tribal art: A record of tradition and continuity. Foundation, New York.

Cavalli-Sforza, L.L.; Feldman, M.W. (1981): Cultural transmission and evolution: A quantitative approach. Princeton University Press, Princeton y New Jersey.

Chapa, T. (1980): La escultura zoomorfa ibérica en piedra (2 vols.). Tesis doctoral, Universidad Complutense de Madrid.

ChapA, T. (1984): Aspectos metodológicos de la tipología arqueológica: Un ejemplo referido a las fíbulas de La Tene. Primeras jornadas de metodología de investigación prehistórica. Soria 1981, Ministerio de Cultura, Madrid: 253-268. 
Cochrane, E. (2004): Explaining cultural diversity in ancient Fiji: The transmission of ceramic variability. Tesis doctoral, Universidad de Hawaii.

(2008): Migration and cultural transmission: Investigating human movement as an explanation for Fijian ceramic change. En O’Brien 2008: 132-145.

Collard, M.; Shennan, S.J.; Tehrani, J. (2006): Branching versus blending in macroscale cultural evolution: A comparative study. En Lipo et al. 2006: 53-64.

Collard, M.; Tehrani, J. (2005): Phylogenesis versus Ethnogenesis in Turkmen cultural evolution. En Mace et al. 2005: 109-131.

Coward, F.; Shennan, S.J.; Colledge, S.; Conolly, J.; Collard, M. (2008): The spread of Neolithic plant economies from the Near East to northwest Europe: A phylogenetic analysis. Journal of Archaeological Science, 35: 42-56.

DARwent, J.; O’Brien, M.J. (2006): Using Cladistics to construct lineages of projectile points from Northeastern Missouri. En Lipo et al. 2006: 185-208.

DARwin, CH.R. (1859): On the origin of species by means of natural selection. John Murray, London. (1871): The descent of man, and selection in relation to sex. John Murray, London.

Diamond, J. (2008) [1998]: Armas, gérmenes y acero. Breve historia de la humanidad en los últimos 13.000 años. DeBols!llo, Sant Llorenç d' Hortons, Barcelona.

Doran, J.E.; Hodson, F.R. (1975): Mathematics and computers in Archaeology. Edinburgh University Press, Edinburgh.

DunNell, R.C. (1978): Style and function: A fundamental dichotomy. American Antiquity, 43 (2): $192-202$. (1980): Evolutionary theory and Archaeology. Advances in Archaeological Method and Theory, 3: 35-99.

DurHam, W.H. (1976): The adoptive significance of cultural behaviour. Human Ecology, 4: 89-117. (1991): Coevolution: Genes, culture and human diversity. Stanford University Press, Stanford, California.

Eerkens, J.W.; Bettinger, R.L.; McElreath, R. (2006): Cultural transmission, Phylogenetics, and the archaeological record. En Lipo et al. 2006: 169-183.

Escacena, J.L. (2010): Darwinismo en almíbar. En Escacena et al.2010: 33-57.

Escacena, J.L.; García Rivero, D.; García Fernández, F.J. (2010) (coords.): Clasificación y Arqueología: Enfoques y métodos taxonómicos a la luz de la evolución darwiniana. Universidad de Sevilla, Sevilla.

FARris, J.S. (1970): Methods for computing Wagner trees. Systematic Zoology, 19: 83-92.

FERNÁNDEZ Martínez, V.M. (1985): La seriación automática en Arqueología: Introducción histórica y aplicaciones. Trabajos de Prehistoria, 42: 9-49.

Forster, P.; Renfrew, C. (2006) (eds.): Phylogenetic methods and the prehistory of languages. McDonald Institute Monographs, Cambridge.

García Rivero, D. (2010a): Evolución cultural y filogenias en Arqueología. El caso de los denominados ídolos placa prehistóricos del Suroeste de la Península Ibérica. Tesis doctoral, Universidad de Sevilla. (2010b): Introducción a la teoría de la clasificación y a las escuelas taxonómicas (Fenética, Cladística y Taxonomía evolutiva). En Escacena et al.2010: 61-94.

Goloboff, P.A. (2003): Parsimony, likelihood, and simplicity. Cladistics, 19: 91-103.

Gould, S.J. (1987): An urchin in the storm. W.W. Norton \& Company, New York. (2004) [2002]: La estructura de la teoría de la evolución. Tusquets, Barcelona.

Gray, R.D; AtKInson, Q.D. (2003): Language tree divergence times support the Anatolian theory of Indo-European origin. Nature, 426: 435-439.

Gray, R.D.; GreEnhiLl, S.J.; Ross, R.M. (2007): The pleasures and perils of darwinizing culture (with phylogenies). Biological Theory, 2 (4): 360-375.

GraY, R.D.; Jordan, F. (2000): Language trees support the Express-train sequence of Austronesian expansion. Nature, 405: 1052-1055.

Greenhill, S.J.; Currie, T.E.; Gray, R.D. (2009): Does horizontal transmission invalidate cultural phylogenies? Proceedings of the Royal Society B, 276: 2299-2306.

Greenhill, S.J.; Gray, R.D. (2005): Testing population dispersal hypotheses: Pacific settlement, phylogenetic trees and Austronesian languages. En Mace et al. 2005: 31-52.

Harmon, M.J., Vanpool, T.L.; Leonard, R.D., Vanpool, C.S.; Salter, L.A. (2006): Reconstructing the flow of information across time and space: A phylogenetic analysis of ceramic traditions from prehispanic Western and Northern Mexico and the American Southwest. En Lipo et al. 2006: 209-229. 
Hart, J.P.; Terrell, J.E. (2002) (eds.): Darwin and Archaeology. A handbook of key concepts. Bergin \& Garvey, Westport, Connecticut.

Hennig, W. (1950): Grundzüge einer Theorie der phylogenetischen Systematik. Deutscher Zentralverlag, Berlin. (1965): Phylogenetic Systematics. Annual Review of Entomology, 10: 97-116.

(1966): Phylogenetic Systematics. Illinois University Press, Illinois.

Holden, C.J. (2006): The spread of Bantu languages, farming, and pastoralism in Sub-Equatorial Africa. En Lipo et al. 2006: 249-267.

Holden, C.J.; Meade, A.; Pagel, M. (2005): Comparison of maximum parsimony and Bayseian Bantu language trees. En Mace et al. 2005: 53-65.

Holder, M.; Lewis, P.O. (2003): Phylogeny estimation: Traditional and Bayesian approaches. Nature Reviews Genetics, 4 (4): 275-284.

Jones, W. (1786): Third anniversary discourse 'On the Hindus'. Reimpreso en The Collected Works of Sir William Jones, 1807, John Stockdale, London: 23-46.

Jordan, P.; Mace, T. (2006): Tracking culture-historical lineages: Can 'descendent with modification' be linked to 'association by descent'? En Lipo et al. 2006: 149-167.

Kitching, I.J.; Forey, P.L.; Humphries, C.J.; Williams, D.J. (1998): Cladistics. The theory and practice of parsimony analysis. Systematics Association Publication, 11, Oxford.

Lamarck, J.B. (1809): Philosophie zoologique. Dentu, Paris.

LAskowski, M.; Fitch, W.M. (1989): Evolution of avian ovomucoids and of birds. The Hierarchy of life (B. Fernholm, K. Bremer y H. Jörnvall, eds.), Elsevier Science Publishers, New York y Oxford: 371-387.

Lewis, P.O. (2001): Phylogenetic systematics turns over a new leaf. Trends in Ecology and Evolution, 16 (1): 30-37.

LILLIOS, K. (2004): Esprit (The engraved stone plaque registry and inquiry tool). [URL: http://research2.its.uiowa. edu/iberian/]. Acceso el 27/03/2011.

Lipo, C.P.; O’Brien, M.J.; Collard, M.; Shennan, S.J. (2006) (eds.): Mapping our ancestors: Phylogenetic approaches in Anthropology and Prehistory. Aldine Transaction, New York.

Lipo, C.P. ; O’Brien, M.J.; Collard, M.; Shennan, S.J. (2006b): Cultural phylogenies and explanation: Why historical methods matter. En Lipo et al. 2006: 3-16.

Lyman, R.L.; O’Brien, M.J. (2006): Seriation and Cladistics: The difference between anagenetic and cladogenetic evolution. En Lipo et al. 2006: 65-88.

Mace, R.; Holden, C.J.; Shennan, S.J. (2005) (eds.): The evolution of cultural diversity: A phylogenetic approach. College London University Press, London.

Makarenkov, V.; Legendre, P. (2004): From a phylogenetic tree to a reticulated network. Journal of computational Biology, 11 (1): 195-212.

Margulis, L.; Sagan, D. (2002): Acquiring genomes: A theory of the origins of species. Basic books, New York.

Maschner, H.D.G. (1996) (ed.): Darwinian archaeologies. Plenum Press, New York.

Mayr, E. (1969): Principles of systematic Zoology. McGraw-Hill, New York.

Mayr, E.; Ashlock, P.D. (1991): Principles of systematic Zoology (2a edición, revisada). McGraw Hill International Edition, Singapore.

McDade, L.A. (1992): Hybrids and phylogenetic systematics II. The impact of hybrids on cladistic analysis. Evolution, 46 (5): 1329-1346.

McMullin, E. (1983): Values in science. Proceedings of the Biennial Meeting of the Philosophy of Science Association, 1982 (2): 3-28.

Moore, J.H. (1994): Putting Anthropology back together again: The ethnogenetic critique of cladistic theory. American Anthropologist, 96: 925-948.

Morgan, L.H. (1877): Ancient society. Holt, New York.

Moylan, J.W.; Graham, C.M.; Borgerhoff, M.; Nunn, Ch.L.; Hakansson, N.T. (2006): Cultural traits and linguistic trees: Phylogenetic signal in East Africa. En Lipo et al. 2006: 33-52.

Muscio, H.J. (2010): Transferencia horizontal, cladismo y filogenias culturales. En Escacena et al. 2010 : 225 252. 
NefF, H. (2006): Archaeological-material characterization as phylogenetic method: The case of Copador pottery from Southeastern Mesoamerica. En Lipo et al. 2006: 231-248.

O’Brien, M.J. (1996) (ed.): Evolutionary Archaeology. Theory and application. Utah University Press, Salt Lake City. (2008) (ed.): Cultural transmission and Archaeology. Issues and case studies. Society for American Archaeology, Washington.

O’Brien, M.J.; Holland, T.D.; Fox, G.L. (2003): Evolutionary implications of design and perfomance characteristics of prehistoric pottery. Syle, fuction, transmission. Evolutionary archaeological perspectives (M.J. O'Brien y R.L. Lyman, eds.), Foundations of Archaeological Inquiry, Utah University Press, Salt Lake City: 199-226.

O’Brien, M.J.; LyMAn, R.L. (1999): Seriation, stratigraphy, and index fossils: The backbone of archaeological dating. Kluwer Academic y Plenum, New York.

(2000): Applying Evolutionary Archaeology. A systematic approach. Kluwer Academic y Plenum Publishers, New York. (2003): Cladistics and Archaeology. Utah University Press, Salt Lake City.

O’Brien, M.J.; Lyman, R.L.; Collard, M.; Holden, C.J.; Gray, R.D.; Shennan, S. (2008): Transmission, Phylogenetics, and the evolution of cultural diversity. En O'Brien 2008: 39-58.

Pulliam, H.R.; Dunford, C. (1980): Programmed to learn: An essay on the evolution of culture. Columbia University Press, New York.

Renfrew, C. (1992): Archaeology, Genetics and linguistic diversity. Man, 27: 445-478.

ReXovÁ, K.; FryntA, D.; ZRZAVY, J. (2003): Cladistic analysis of languages: Indo-European classification based on lexicostatistical data. Cladistics, 19: 120-127.

Richerson, P.J.; Boyd, R. (2005): Not by genes alone. How culture transformed human evolution. Chicago University Press, Chicago y London.

Riede, F. (2008): Maglemosian memes: Technological ontogeny, craft traditions, and the evolution of Northern European barbed points. En O’Brien 2008: 178-189.

Rindos, D. (1980): Symbiosis, instability, and the origins and spread of agriculture: A new model. Current Anthropology, 21 (6): 751-772.

(1990) [1984]: Los orígenes de la agricultura. Una perspectiva evolucionista. Bellaterra, Barcelona.

Rivera, M.C.; LAKE, J.A. (2004): The ring of life provides evidence for a genome fusion origin of eukaryotes. Nature, 431: 152-155.

RonQuist, F. (2004): Bayesian inference of character evolution. Trends in Ecology and Evolution, 19 (9): $475-481$.

Ruse, M. (2001) [1999]: El misterio de los misterios. ¿Es la evolución una construcción social? Tusquets, Barcelona.

Sanderson, M.J.; Donoghue, M.J. (1989): Patterns of variation in levels of homoplasy. Evolution, 43 (8): 1781-1795.

Schiffer, M.B. (2008): Transmission processes: A behavioral perspective. En O’Brien 2008: 102-111.

Schleicher, A. (1863): Die Darwinsche Theorie und die Sprachwissenschaft. Böhlau, Weimar.

Service, E.R. (1962): Primitive social organization. Random House, New York.

Shennan, S.J. (2002): Genes, memes and human history. Darwinian Archaeology and cultural evolution. Thames \& Hudson, London.

(2009) (ed.): Pattern and process in cultural evolution. California University Press, Berkeley, California.

Spencer, M; Windram, H.F.; Barbrook, A.C.; Davidson, E.A.; Howe, C.J. (2006): Phylogenetic analysis of written traditions. En Forster y Renfrew 2006: 67-74.

STEWARD, J. (1955): Theory of culture change. Illinois University Press, Urbana.

Teltser, P.A. (1995) (ed.): Evolutionary Archaeology: Methological issues. Arizona University Press, Tucson.

TËmkin, I; Eldredge, N. (2007): Phylogenetics and material cultural evolution. Current Anthropology, 48 (1): 146-153.

Terrell, J.E.; Steward, P.J. (1996): The paradox of human population Genetics at the end of the Twentieth century. Reviews in Anthropology, 26: 13-33.

TYlor, E.B. (1871): Primitive culture. Murray, London.

Van Driem, G. (2001): Languages of the Himalayas: An ethnolinguistic handbook of the Greater Himalayan region (2 vols.). Brill, Leiden. 
Vanpool, T.L.; Palmer, C.T.; Vanpool, C.S. (2008): Horned serpents, tradition, and the tapestry of culture. En O’Brien 2008: 77-90.

White, L.A. (1959): The evolution of culture. McGraw-Hill, New York.

Willey, E.O.; Siegel-Caysey, D.; Brooks, D.R.; FunK, V.A. (1991): The compleat cladist. A primer of phylogenetic procedures. The University of Kansas, Museum of Natural History, Special Publication, 19. Lawrence, Kansas.

YAnG, Z.; Goldman, N. (2008): Statistical and computational challenges in molecular Phylogenetics and evolution. Royal Society Publishing, London. 